Article

\title{
Improvement of Performance Level of Steel Moment-Resisting Frames Using Tuned Mass Damper System
}

\author{
Masoud Dadkhah ${ }^{1}\left(\mathbb{D}\right.$, Reza Kamgar $^{1}{ }^{(\mathbb{D}}$, Heisam Heidarzadeh ${ }^{1}{ }^{\circledR}$, \\ Anna Jakubczyk-Gałczyńska ${ }^{2, *(D)}$ and Robert Jankowski ${ }^{2}$ (D) \\ 1 Department of Civil Engineering, Shahrekord University, Shahrekord 88186-34141, Iran; \\ masouddadkhah1354@gmail.com (M.D.); kamgar@sku.ac.ir (R.K.); heidarzadeh@sku.ac.ir (H.H.) \\ 2 Faculty of Civil and Environmental Engineering, Gdansk University of Technology, 80-233 Gdansk, Poland; \\ jankowr@pg.edu.pl \\ * Correspondence: annjakub@pg.edu.pl
}

Received: 2 April 2020; Accepted: 12 May 2020; Published: 14 May 2020 updates

\begin{abstract}
In this paper, parameters of the tuned mass dampers are optimized to improve the performance level of steel structures during earthquakes. In this regard, a six-story steel frame is modeled using a concentrated plasticity method. Then, the optimum parameters of the Tuned Mass Damper (TMD) are determined by minimizing the maximum drift ratio of the stories. The performance level of the structure is also forced to be located in a safety zone. The incremental dynamic analysis is used to analyze the structural behavior under the influence of the artificial, near- and far-field earthquakes. The results of the investigation clearly show that the optimization of the TMD parameters, based on minimizing the drift ratio, reduces the structural displacement, and improves the seismic behavior of the structure based on Federal Emergency Management Agency (FEMA-356). Moreover, the values of base shear have been decreased for all studied records with peak ground acceleration smaller or equal to $0.5 \mathrm{~g}$.
\end{abstract}

Keywords: dynamic analysis; steel frames; Tuned Mass Damper; optimization; drift ratio

\section{Introduction}

Structural disruption resulting in dangerous vibrations might be inevitable due to dynamic loads, such as wind and earthquake (see, for example, [1-4]). The use of different methods to minimize these vibrations and make structures more resistant to dynamic loads is growing day by day [5-8]. Accordingly, many researchers have focused their investigations on studying the effectiveness of different control systems, including dampers, base isolation, etc. [9-15]. Some of the most popular types of dampers include the Tuned Mass Damper (TMD; see [16-19]) and the Tuned Liquid Damper (TLD) [20]. Both are known as passive control systems. These vibrations control systems can absorb some of the input energy due to the earthquake motion [21]. There are also other passive control vibration systems, such as friction tuned mass damper (see [22-24]), viscous damper (see [25-27]), magnetorheological damper (see $[28,29]$ ), tuned mass-damper-inerter (see $[30,31])$, and pendulum tuned mass damper (see [32]).

Numerous researchers used various meta-heuristic algorithms to optimize the parameters of the TMD systems. Among all existing meta-heuristic algorithms, some lead to more suitable results for nonlinear optimization models (see [33], for example). Some researchers used the algorithm of the Genetic Algorithm (GA) and Charged System Search (CSS) to optimize the parameters of the TMD subjected to the critical earthquake [16-18,34-38]. Kamgar et al. [17] optimized the parameters of the 
TMD system using the Grey Wolf Optimization (GWO) method. The results of their research show that the maximum structural responses (i.e., roof displacement and stroke ratio) may be reduced by optimizing parameters of the TMD system and the dynamic behavior of the structure in terms of minimizing the input, and kinematic energies can be improved. Khatibinia et al. [19] investigated the optimum parameters of the TMD system intending to minimize the sum of the root-mean-square of drifts in the frequency domain under the critical earthquake for a 10-story shear building. Wong [39] evaluated the problem of the input energy dissipation for non-elastic structures equipped with the TMD. The author demonstrated the effectiveness of the TMD system in reducing the dynamic responses of the structures and concluded that the control of the structure using the TMD system could absorb more input energy, and subsequently, could damp the absorbed energy. This damping energy improves the dynamic performance of the structure. Nigdeli et al. [40] optimized the parameters of the TMD system based on the minimization of the acceleration transfer function. The results of their research indicate that the use of meta-heuristic algorithms to optimize the TMD parameters is more effective than classical methods. Kamgar et al. [16] calculated the optimum parameters of the TMD system, taking into account the soil-structure interaction effect adapting the whale optimization algorithm. They showed that the soil type and the objective function were very effective in the optimal parameters obtained for the TMD system.

An accurate estimation of the dynamic capacity of structures is one of the most critical challenges for researchers. The use of the Incremental Dynamic Analysis (IDA) is essential to evaluate accurately the dynamic performance of structures subjected to earthquake loads. For the first time, Bertero in [41] presented the IDA's time history analysis by scaling the earthquake records step by step and incrementally. Vamvatsikos and Cornell [42] introduced the IDA analysis as a method often used today. The most important advantage of the IDA analysis, in comparison with other methods, is the high ability of this type of analysis to show the actual attitude of the structure from the elastic state to the inelastic one. Additionally, this method can consider structural instability due to entering the structure from the elastic state into the inelastic one [43]. The optimization algorithm has also been utilized to design semi-rigid steel frames and reinforced concrete sections (see [44,45]).

In the present paper, a moment-resisting steel frame equipped with the TMD system is selected $($ see $[39,46])$. The nonlinear behavior of the joints is modeled using zero-length spring elements and rotational springs at the end of the beam-column elements [47]. Additionally, OpenSees software is used to simulate the dynamic structural behavior. Herein, the parameters of the TMD system are optimized to minimize the maximum drift ratio of structures subjected to earthquakes. Then, the effect of an optimal TMD on the development of the nonlinear seismic efficiency of steel moment-resisting frames is investigated. The main aim of the paper is to investigate a system that, in addition to lower cost, can improve the performance of the structure in comparison with the other vibration control systems.

The authors of previously published papers focused on the optimization of the parameters of the TMD system by calculating the optimal values of the TMD system numerically using the optimization algorithms [16-19,34-40]. The most important question is whether these optimal values can still control the dynamic responses of structures by changing the characteristics of the earthquake. Therefore, in this paper, the controlled structure is subjected to several incremental dynamics analyses using the optimal values for the TMD system to answer this question. The answer to the question that the controlled structure can withstand large earthquakes is vital in this regard. Additionally, the other question is whether the controlled structure can minimize the structural responses in other ranges of the peak ground acceleration (PGA) rather than the studied earthquakes? In fact, the structure is first designed to an earthquake with the PGA equal to $1 \mathrm{~g}$ ( $\mathrm{g}$ is the acceleration of gravity) using a TMD system. Then the responses of the controlled structure are examined using the incremental dynamic analyses by changing the PGA from $0.1 \mathrm{~g}$ to $1 \mathrm{~g}$. Additionally, in this paper, for the first time, the Life Safety constraint is introduced to keep the structure in a safe zone based on FEMA-356 [48]. 


\section{Optimal Design of the TMD System}

The paper is focused on an optimization method of the parameters of the TMD system (including damping, stiffness, and mass). The optimization is conducted according to a reduction in the maximum drift ratio of structures exposed to earthquakes. This criterion is upon the limitation proposed by FEMA-356 [48] for the maximum allowable drift ratio of the steel moment-resisting frame. Therefore, the optimal design of the TMD system for a steel moment-resisting frame can be formulated as:

$$
\begin{aligned}
& \text { Find: } \quad M_{d}, K_{d}, C_{d} \\
& \text { Minimize : } \quad \max \left(\frac{\max \mid \text { drift }\left.\right|_{\text {with }} \text { TMD }}{\max \mid \text { drift }\left.t_{i}\right|_{\text {without TMD }}}\right) \times 100, \quad i=1,2,3, \ldots, n \\
& \text { Subjected to: } M_{d}^{\min } \leq M_{d} \leq M_{d}^{\max } \\
& K_{d}^{\min } \leq K_{d} \leq K_{d}^{\max } \\
& C_{d}^{\min } \leq C_{d} \leq C_{d}^{\max } \\
& \max \left(\left|u_{d}(t)-x_{\text {roof }}(t)\right|\right) \leq 1000(\mathrm{~mm}) \\
& \max \left|d r i f t_{i}\right|_{\text {with } T M D} \leq 0.025, \quad i=1,2,3, \ldots, n
\end{aligned}
$$

where $M_{d}, K_{d}$ and $C_{d}$ indicate the mass, stiffness, and damping coefficient for the TMD system, respectively. $M_{d}^{\min }, M_{d}^{\max }, K_{d}^{\min }, K_{d}^{\max }, C_{d}^{\min }$ and $C_{d}^{\max }$ are the lower and upper bounds of the TMD mass, stiffness and damping constants, respectively. These lower and upper bounds have been selected based on the work [46].

\section{Passive Control Systems}

Currently, the control of the seismic response of the structures subjected to dynamic loads is a method that can help engineers to design structures. Among various methods of seismic control, the passive control method is one of the most popular, due to the lower cost of construction and maintenance. One of the passive control systems is the application of TMD. This system, consisting of a mass, damping, and linear spring, is typically installed on the roof of the structure. The system reduces the dynamic response of the structure by affecting its dominant mode. The mass of the TMD system moves with a different phase relative to the structure, and it improves the seismic structural response by the dissipation of energy [49-51]. The efficiency of the TMD system is highly dependent on its parameters. Therefore, the optimization of these parameters for the seismic control of tall structures against dynamic loads is one of the crucial issues.

A schematic view of the TMD system is exhibited in Figure 1. In this study, the Water Cycle Algorithm (WCA) has been used to reduce the relative displacement of the considered frame by the LS performance level presented in FEMA-356 [48] (i.e., the maximum allowable drift ratio for the steel moment-resisting frame is $2.5 \%$ ). Therefore, the dynamic capacity and the performance of the controlled structure have been investigated using the IDA analysis. 


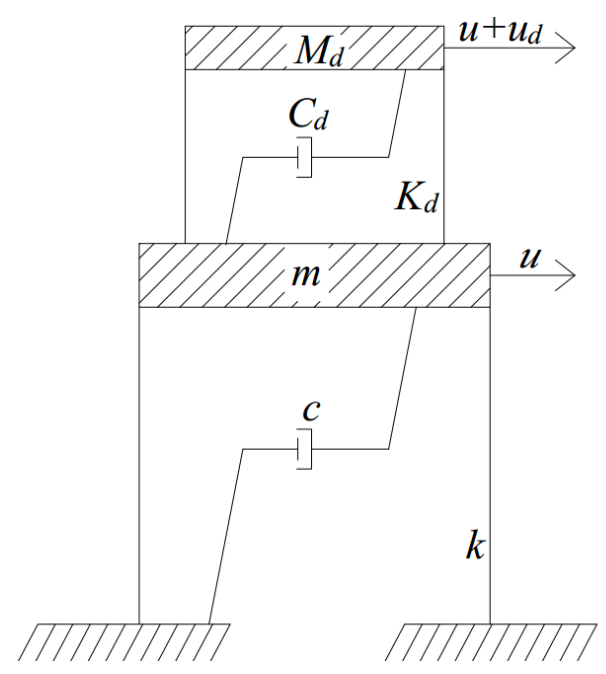

Figure 1. Schema of a single-degree-of-freedom system controlled by a TMD system.

\section{Water Cycle Algorithm (WCA)}

The optimization algorithms are generally based on natural phenomena, social events, and physical laws to solve different problems. The clever way used by these algorithms for computation is based on iterations to improve the performance of a system. Eskandar et al. [52] proposed WCA based on the rotational cycle of water in nature (i.e., the flow of streams toward the sea). The flow of water in the environment is like a tree or root of a tree. The small branches of this stream are small rivers that form the rivers by joining together. A sea is a place with the lowest elevation, and eventually, the rivers flow into it. The initial population is computed to formulate the equations of the water cycle algorithm, as in other population-based algorithms. Detailed information has been illustrated in [52]. The streams in the rivers arise from existing differences in the levels of two points, i.e., water flows from higher altitudes to lower altitudes. After rain comes down, the streams and rivers are formed and move to the lowest area, usually to the sea. The water cycle in nature consists of three processes: (1) the precipitation that creates the initial population, (2) the surface movement of the rivers and streams to the sea, and (3) the procedure of the evaporation and condensation.

Therefore, to formulate the first step, Equations (2) and (3) are used.

$$
\begin{gathered}
\text { Raindrop }=\left[x_{1}, x_{2}, x_{3}, \ldots, x_{N}\right] \\
\text { Population of raindrops }=\left[\begin{array}{c}
\text { Raindrops } 1 \\
\text { Raindrops }_{2} \\
\text { Raindrops } \\
\\
\vdots \\
\text { Raindrops } \\
N_{p o p}
\end{array}\right]= \\
{\left[\begin{array}{ccccc}
x_{1}^{1} & x_{2}^{1} & x_{3}^{1} & \ldots & x_{N_{\text {var }}}^{1} \\
x_{1}^{2} & x_{2}^{2} & x_{3}^{2} & \ldots & x_{N_{\text {var }}}^{2} \\
\vdots & \vdots & \vdots & \vdots & \vdots \\
x_{1}^{N_{p o p}} & x_{2}^{N_{p o p}} & x_{3}^{N_{p o p}} & \ldots & x_{N_{\text {var }}}^{N_{\text {var }}}
\end{array}\right]}
\end{gathered}
$$

where the values of the decision variables $\left(x_{1}, x_{2}, x_{3}, \ldots, x_{N}\right)$ can be expressed by several floating points of the problem. The cost of Raindrop is also obtained by Equation (4) as follows:

$$
C_{i}=\operatorname{Cost}_{i}=f\left(x_{1}^{i}, x_{2}^{i}, \ldots, x_{N_{\mathrm{var}}}^{i}\right) i=1,2,3, \ldots, N_{\text {pop }}
$$


in which $N_{\text {pop }}$ and $N_{\text {var }}$ represent the stream population as the initial population and some design variables, respectively. Cost $t_{i}$ shows the cost estimation function of the variables, see for example [53]. Firstly, the parameter $N_{p o p}$ is generated, and a number is selected for the $N_{s r}$ parameter as the best value (minimum values) for the rivers and sea in the first step. The number of rivers and the sea is calculated as a variable $N_{s r}$ as follows:

$$
\begin{gathered}
N_{s r}=\text { Number of Rivers }+\underbrace{1}_{\text {Sea }} \\
N_{\text {Raindrop }}=N_{\text {pop }}-N_{s r}
\end{gathered}
$$

The parameter $N_{\text {Raindrop }}$ is the rest of the population that make up possible routes to the sea or the rivers. Equation (7) is used depending on the intensity of the flow to determine and assign raindrops in rivers and sea:

$$
N S_{n}=\text { Round }\left\{\left|\frac{\text { Cost }_{n}}{\sum_{i=1}^{N_{s r}} \text { Cost }_{i}}\right| \times N_{\text {Raindrops }}\right\}, n=1,2, \ldots, N_{S R}
$$

in which $N S_{n}$ is a number of streams that flow into some specific rivers or the sea. Besides, the new positions of the streams and rivers are also expressed as follows:

$$
\begin{gathered}
\vec{X}_{\text {Stream }}^{t+1}=\vec{X}_{\text {Stream }}^{t}+\text { rand } \times C \times\left(\vec{X}_{\text {River }}^{t}-\vec{X}_{\text {Stream }}^{t}\right) \\
\vec{X}_{\text {River }}^{t+1}=\vec{X}_{\text {River }}^{t}+\text { rand } \times C \times\left(\vec{X}_{\text {Sea }}^{t}-\vec{X}_{\text {River }}^{t}\right)
\end{gathered}
$$

in which rand is a uniformly distributed random number from the interval $\langle 0,1\rangle$. Additionally, the parameter $C$ has a number between 1 and 2 , and it is usually close to 2 . If the evaporation conditions are taken into account, it can help the algorithm to prevent premature convergence:

$$
\begin{aligned}
& I f\left\|\vec{X}_{\text {Sea }}(t)-\vec{X}_{\text {River }}^{i}(t)\right\|<d_{\text {max }}(t) \text { orrand } \in\langle 0,1\rangle, \\
& n=1,2,3, \ldots, N_{s r}-1
\end{aligned}
$$

where $d_{\max }$ is a small number (close to zero). It indicates that the river is connected to the sea when the river is away from the sea less than the value of $d_{\max }$. The parameter $d_{\max }$ can control the optimal solution, and its value is updated as follows:

$$
d_{\max }(t+1)=d_{\max }(t)-\frac{d_{\max }(t)}{\text { MaxIteration }}
$$

Additionally, after considering the evaporation conditions for the algorithm, the new streams are randomly generated in the search space as follows:

$$
\vec{X}_{\text {Stream }}^{\text {New }}=L B+\text { rand } \cdot(U B-L B)
$$

in which the parameters $U B, L B$ are the minimum and maximum boundary conditions, respectively. Then, the river flowing to the sea is selected from the best new raindrops, and the other remaining new raindrops create streams that can flow to the river or sea. Equation (13) is utilized for the streams that have flowed to the sea to check the computational performance and convergence rate of the optimization problem:

$$
\vec{X}_{\text {Stream }}^{\text {New }}=X_{\text {sea }}+\sqrt{\mu} \times \operatorname{randn}\left(1, N_{\text {var }}\right)
$$

where $\mu$ is a coefficient, and the value of 0.1 has been proposed for it in [52]. 


\section{Incremental Dynamic Analysis (IDA)}

IDA is an accurate analysis method that is capable of estimating the seismic behavior of structures subjected to different earthquakes. One of the principles of the functional design of structures is the use of the nonlinear dynamic capacity of load-bearing members in the design of structures.

The stiffness values of the structural elements decrease when a severe dynamic load is applied to the structure. As a result, the stiffness matrix of the structure will decrease when the plastic joints are formed in the members. Finally, it results in the redistribution of the forces among the members of the structure. Finally, the structure experiences more deformation because of yielding in some elements, and it leads to more significant energy absorption and damping.

In IDA, a structure is subjected to a mapping acceleration. The mapping acceleration is selected from an earthquake. Then, the earthquake is scaled so that its maximum acceleration is equal to $1 \mathrm{~g}$. Hence, the structure is subjected to the scaled earthquake record. Next, the maximum acceleration is added to the value of $0.2 \mathrm{~g}$, and the structure is re-analyzed. This process continues until the maximum acceleration of the earthquake is equal to $1 \mathrm{~g}$. Finally, the IDA curve is plotted for the frame and earthquake. The IDA shows the nonlinear dynamic response of the structure against the intensity of the seismic excitation.

\section{Modeling and Verification}

A six-story steel frame is selected in this study (see Figure 2). The frame has already been studied by several researchers (see $[39,46]$ ). A finite element software named OpenSees [47] is used to model the frame. Additionally, the modified Ibarra-Krawinkler (IMK) deterioration model (see [54-56]) is utilized to simulate the nonlinear behavior of the plastic joints. According to this constitutive model, the zero-length elements are considered as concentrated plasticity at the beam-column connections. The IMK model takes into account the cyclic response of the springs, which shows the nonlinear behavior of the frame. Due to the presence of the gravitational loads, as well as the TMD mass, the P-delta effect must be taken into account to consider the enhanced structural responses. For this purpose, a virtual column with truss elements attached to the base of the structure is analyzed. Additionally, all columns are considered to be fixed at the base of the structure. Since the rotational springs and frame elements are connected in series, the stiffness of the rotational elements must be modified in such a way that the stiffness value of elements and the actual stiffness of the frame are the same. For this purpose, the stiffness of the rotational springs is considered to be $n=10$ times higher than the rotational stiffness of the elastic elements. The stiffness and also the moment of inertia of the elastic element are multiplied into the $(n+1) / n$. Finally, to match the nonlinear behavior of the elements and the actual behavior of the frame, the strain coefficient of the plastic joint should be modified according to Equation (14)—see [54-57].

$$
\alpha_{s, \text { spring }}=\alpha_{s, m e m} /\left(1+n \cdot\left(1-\alpha_{s, m e m}\right)\right)
$$

where $\alpha_{s, m e m}$ shows the real strain coefficient of the frame, and $\alpha_{s, s p r i n g}$ is the strain hardening coefficient of the rotational spring. All beam elements are subjected to the uniformly distributed load equal to $21.89 \mathrm{kN} / \mathrm{m}$. Additionally, the following relations (Equations (15)-(22)) are used to determine the parameters required in the definition of the behavioral curve of the rotational springs [54-57]:

$$
\begin{gathered}
\theta_{p}=0.318\left(\frac{h}{t_{w}}\right)^{-0.55}\left(\frac{b_{f}}{2 t_{w}}\right)^{-0.345}\left(\frac{L_{b}}{r_{y}}\right)^{-0.023}\left(\frac{L}{d}\right)^{0.09}\left(\frac{c_{\text {unit }}^{1} \cdot d}{533}\right)^{-0.33}\left(\frac{c_{\text {unit }}^{2} \cdot F_{y}}{355}\right)^{-0.13} \\
d \geq 21 \text { in } \\
\theta_{p c}=5.63\left(\frac{h}{t_{w}}\right)^{-0.565}\left(\frac{b_{f}}{2 t_{w}}\right)^{-0.8}\left(\frac{c_{\text {unit }}^{1} \cdot d}{533}\right)^{-0.28}\left(\frac{c_{\text {unit }}^{2} \cdot F_{y}}{355}\right)^{-0.43} \\
d \geq 21 \text { in }
\end{gathered}
$$




$$
\begin{gathered}
\wedge=536\left(\frac{h}{t_{w}}\right)^{-1.26}\left(\frac{b_{f}}{2 t_{w}}\right)^{-0.525}\left(\frac{L_{b}}{r_{y}}\right)^{-0.13}\left(\frac{c_{\text {unit }}^{2} \cdot F_{y}}{355}\right)^{-0.291} \\
\theta_{p c}=7.5\left(\frac{h}{t_{w}}\right)^{-0.61}\left(\frac{b_{f}}{2 t_{w}}\right)^{-0.71}\left(\frac{L_{b}}{r_{y}}\right)^{-0.11}\left(\frac{c_{\text {unit }}^{1} \cdot d}{533}\right)^{-0.161}\left(\frac{c_{\text {uning }}^{2} \cdot F_{y}}{355}\right)^{-0.32} \\
\theta_{p}=0.0865\left(\frac{h}{t_{w}}\right)^{-0.365}\left(\frac{b_{f}}{2 t_{w}}\right)^{-0.14}\left(\frac{L}{d}\right)^{0.34}\left(\frac{c_{\text {unit }}^{1} \cdot d}{533}\right)^{-0.721}\left(\frac{c_{\text {unit }}^{2} \cdot F_{y}}{355}\right)^{-0.23} \\
d<21 \text { in } \\
\wedge=495\left(\frac{h}{t_{w}}\right)^{-1.34}\left(\frac{b_{f}}{2 t_{w}}\right)^{-0.595}\left(\frac{c_{\text {unit }}^{2} \cdot F_{y}}{355}\right)^{-0.36} \\
d<21 \text { in } \\
M_{y}=1.17 \cdot Z \cdot F_{y} \\
\theta_{y}=\left(1.17 \cdot Z \cdot F_{y} / 6 E I\right) / L
\end{gathered}
$$

where $h$ is the web depth; $b_{f}$ is the width flange of a beam; $L_{b}$ is the distance from the column face to the nearest lateral brace; $d$ is the beam depth. Additionally, $r_{y}$ shows the radius of gyration about the $y$-axis of the beam, and $t_{w}$ is the web thickness of the beam. The parameter $Z$ is the plastic section modulus, and $F_{y}$ shows the expected yield strength. Moreover, the parameters $c_{\text {unit }}^{1}$ and $c_{\text {unit }}^{2}$ are the two coefficients for unit conversion, while $E$ depicts Young's modulus, and $I$ shows the moment of inertia. The parameters $\theta_{p}, \theta_{p c}, \theta_{y}$, exhibit pre-capping plastic rotation in monotonic loading, post-capping plastic rotation, and yield rotation, respectively. The parameter $L$ is the beam shear span (distance from plastic hinge location to the point of inflection); $\Lambda$ shows the capacity of the reference cumulative rotation, and $M_{y}$ is the effective yield moment [56].

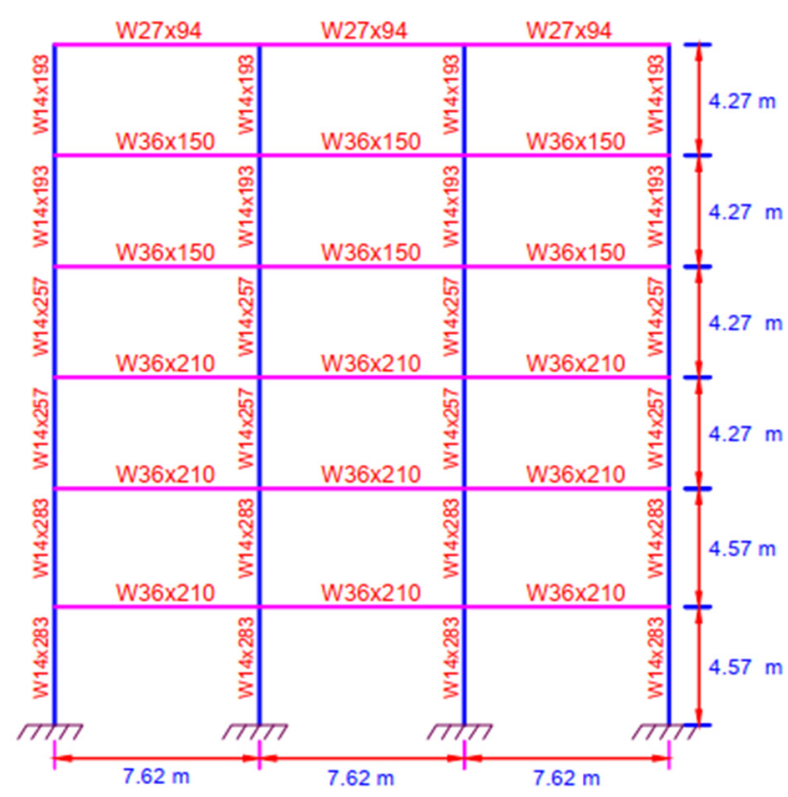

Figure 2. Six-story steel moment-resisting frame.

The mass of all stories and also the values of the damping ratio for all modes are assumed to be equal to $m=300,000 \mathrm{~kg}$, and 3\%, respectively. The Young's modulus is $200 \mathrm{MPa}$. The maximum allowable stroke for TMD is considered to be equal to $1000 \mathrm{~mm}$. The values for the first six natural frequencies of the six-story steel frame are calculated numerically and compared with the results presented by Wong in [39] and Bilondi et al. in [46] to validate the model (see Table 1). It can be seen from Table 1 that the differences are negligible. It confirms the accuracy of the modeling approach. 
Table 1. The benchmark Special Moment Resisting Frame's (SMRF's) natural frequencies of vibration.

\begin{tabular}{cccc}
\hline \multirow{2}{*}{ Mode Number } & \multicolumn{3}{c}{ Natural Periods of Vibration (rad/s) } \\
\cline { 2 - 4 } & Wong [39] & Bilondi et al. [46] & Present Study \\
\hline 1 & 5.15 & 5.07 & 5.07 \\
2 & 14.28 & 13.96 & 14.22 \\
3 & 25.13 & 25.13 & 25.13 \\
4 & 34.91 & 34.91 & 34.91 \\
5 & 44.88 & 44.88 & 44.88 \\
6 & 57.12 & 57.12 & 57.12 \\
\hline
\end{tabular}

Additionally, the time history of cumulative hysteresis energy, $E_{h}$, (see Equation (23)) for the structure with (W) and without (W/O) TMD are compared with [46] (see Figure 3) subjected to the Northridge earthquake (see Figure 4). The values of mass, stiffness, and damping ratio of the TMD system are considered to be equal to $180,000 \mathrm{~N} \cdot \mathrm{s}^{2} / \mathrm{m}$ ), 5,264,000 N/m, and 0.05 based on [46], respectively. Figure 3 also shows the verification of the result obtained by this study and described in [46]:

$$
E_{h}=\sum_{k=1}^{n_{e}} E_{h, k}
$$

where $E_{h, k}, k$, and $n_{e}$ present the summation of work done by internal forces (e.g., moment, axial, shear), an integer counter, and the number of elements, respectively.

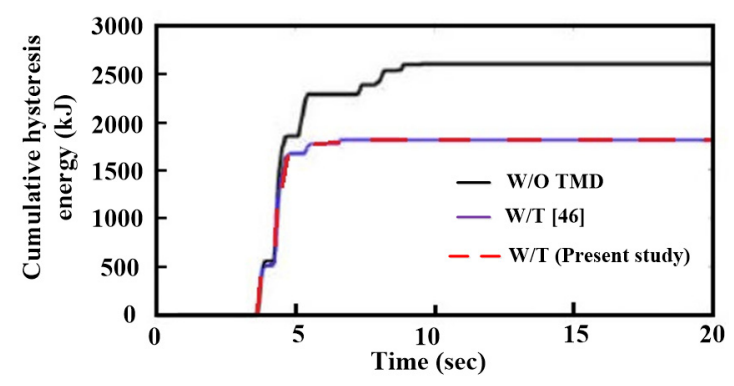

Figure 3. The cumulative hysteresis energy of the controlled and uncontrolled six-story steel frame building.

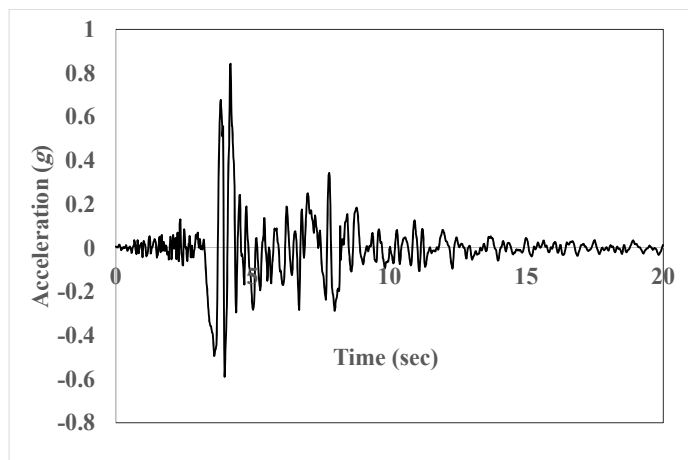

Figure 4. Acceleration time history of the Northridge 1994 earthquake.

In this paper, to optimize and analyze the structure dynamically, several real earthquakes and one artificial earthquake are selected (see Table 2). Figure 5 shows the acceleration time history of the artificial earthquake. The artificial earthquake is calculated using the Gaussian White Noise process and based on the Kanai-Tajimi filter and power spectral density function (PSDF) [58-60]: 


$$
\begin{aligned}
& S_{\text {Kanai-Tajimi }}(\omega)=S_{0}\left[\frac{\omega_{g}^{4}+\left(2 \times \omega_{g} \times \xi_{g} \times \omega\right)^{2}}{\left(\omega^{2}-\omega_{g}^{2}\right)^{2}+\left(2 \times \omega_{g} \times \xi_{g} \times \omega\right)^{2}}\right] \\
& S_{0}=\frac{0.03 \times \xi_{g}}{\pi \times \omega_{g} \times\left(4 \times \xi_{g}^{2}+1\right)}
\end{aligned}
$$

where $S_{0}, \omega_{g}$, and $\xi_{g}$ are the intensity of the PSDF, frequency, and damping of the soil, respectively. In this paper, $\omega_{g}$ and $\xi_{g}$ are considered to be equal to $25.13 \mathrm{rad} / \mathrm{s}$ and $0.8 \mathrm{rad} / \mathrm{s}$, respectively, based on [61], which indicates that the structure has been located on the stiff soil. The strong ground motion of the artificial earthquake is big enough, and it can be used in the dynamic analysis of the structures based on Uniform Building Code 97 [62].

It should be noted that Chandler's classification has been considered in the selection of the earthquake to cover all existing categories for the earthquakes (see $[8,63])$.

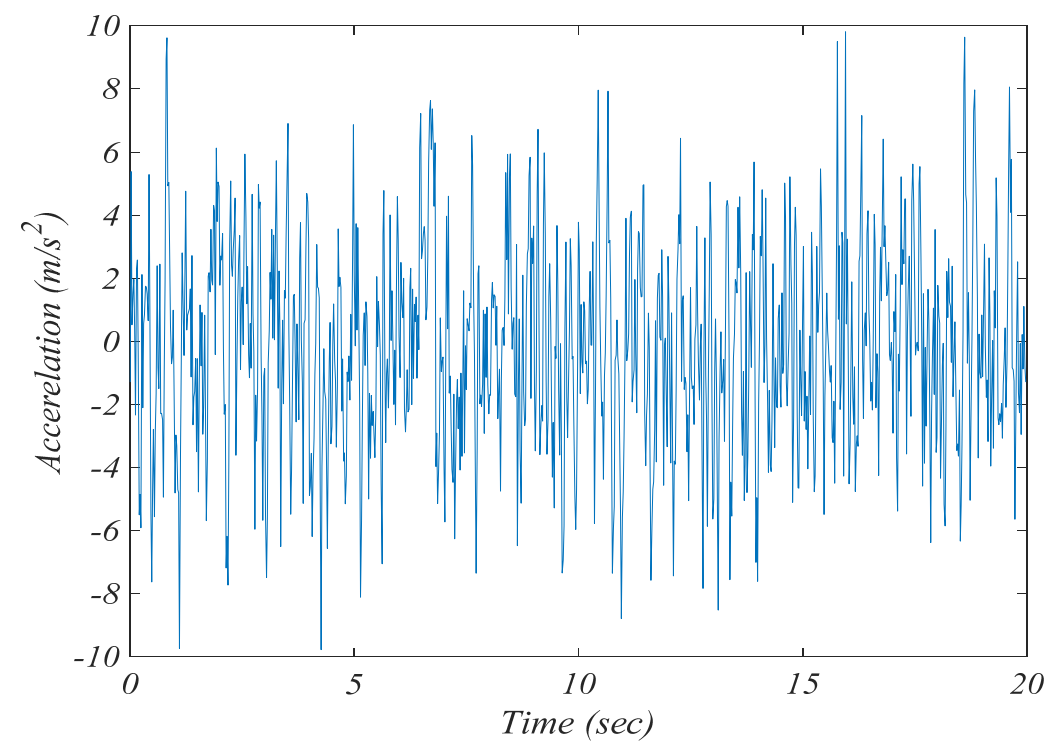

Figure 5. Acceleration time history of an artificial earthquake.

\begin{tabular}{|c|c|c|c|c|c|c|c|}
\hline Abbreviation & $\mathrm{AE}$ & NE3 & NE2 & NE1 & FE3 & FE2 & FE1 \\
\hline Earthquake & $\begin{array}{c}\text { An } \\
\text { artificial } \\
\text { earthquake }\end{array}$ & $\begin{array}{l}\text { Kocaeli } \\
\text { Turkey }\end{array}$ & $\begin{array}{l}\text { Gazli } \\
\text { USSR }\end{array}$ & $\begin{array}{l}\text { Chi-Chi } \\
\text { Taiwan }\end{array}$ & $\begin{array}{l}\text { Superstition } \\
\text { Hills-02 }\end{array}$ & San Fernando & $\begin{array}{l}\text { Duzce } \\
\text { Turkey }\end{array}$ \\
\hline Station & - & Arcelik & Karakyr & CHY101 & $\begin{array}{c}\text { El Centro } \\
\text { Imp. Co. } \\
\text { Cent }\end{array}$ & $\begin{array}{l}\text { LA-Hollywood } \\
\text { Stor FF }\end{array}$ & Bolu \\
\hline $\begin{array}{l}\text { PGA } \\
(\mathrm{g})\end{array}$ & 1 & 1 & 1 & 1 & 1 & 1 & 1 \\
\hline PGA/PGV $(\mathrm{g} \cdot \mathrm{s} / \mathrm{m})$ & 0.206 & 0.601 & 1.277 & 0.630 & 0.743 & 1.035 & 1.32 \\
\hline $\begin{array}{l}\text { Strong ground motion } \\
\text { duration (s) }\end{array}$ & 18 & 13.265 & 6.956 & 28.55 & 27.99 & 13.15 & 8.55 \\
\hline Predominant Period (s) & 0.2 & 0.28 & 0.14 & 1.08 & 0.22 & 0.24 & 0.32 \\
\hline Total time duration (s) & 19.98 & 29.995 & 13.0878 & 88.995 & 59.99 & 79.44 & 55.89 \\
\hline Arias Intensity (m/s) & 33.311 & 15.370 & 7.599 & 12.291 & 8.646 & 13.396 & 6.806 \\
\hline
\end{tabular}

Table 2. Characteristics of the selected scaled earthquakes. 


\section{Results and Discussion}

\subsection{Optimization of the Parameters of the TMD System}

In this paper, a six-story steel frame equipped with the TMD system is studied. One of the most critical issues with the TMD systems is to determine their optimal parameters. Therefore, different methods are used to optimize these parameters. Among them, the meta-heuristic algorithms are commonly used due to the current uncertainty of the mathematical problem as well as different scenarios used for the objective function. In general, all meta-heuristic algorithms start from a local search and eventually reach the desired values. In this paper, a WCA (see Section 4) meta-heuristic algorithm has been selected because of its ability to solve constraint problems. Therefore, the optimum parameters for the TMD system are calculated by WCA to minimize the relative displacement of the stories adapted to the LS performance level presented by FEMA-356 [48]. The optimum parameters of the TMD system exposed to the near- and far-field earthquakes, as well as to the artificial earthquake, have been presented in Table 3.

In fact, the water cycle algorithm has been used to optimize the parameters of the TMD system subjected to the far-, near-field, and artificial earthquakes. Equations (2)-(13) are utilized to perform an optimization problem using Matlab software. Additionally, Equation (1) is used to make an optimization problem with an upper and lower boundary for the optimization variables. Table 3 shows the optimum parameters of the TMD system subjected to different studied earthquakes.

Table 3. Optimum parameters achieved for TMD subjected to the drift ratio constraint.

\begin{tabular}{|c|c|c|c|}
\hline Earthquake & $K_{t m d}(\mathrm{~N} / \mathrm{mm})$ & $C_{t m d}(\mathrm{~N} \cdot \mathrm{s} / \mathrm{mm})$ & $M_{t m d}\left(\mathrm{~N} \cdot \mathrm{s}^{2} / \mathrm{mm}\right)$ \\
\hline FE1 & 404.94 & 770.18 & 180 \\
\hline FE2 & 543.76 & 304.28 & 180 \\
\hline FE3 & 490.1 & 942.89 & 180 \\
\hline NE1 & 421.67 & 1753.1 & 180 \\
\hline NE2 & 315.87 & 972.87 & 141 \\
\hline NE3 & 405.02 & 500.0 & 180 \\
\hline $\mathrm{AE}$ & 405.47 & 935.66 & 180 \\
\hline
\end{tabular}

\subsection{The Structural Seismic Performance}

The results for the structure controlled with the TMD system are shown in Table 4. As it is observed from the table, the reduction in the base shear is less than $3.49 \%$ under different earthquakes, even though the base shear has increased slightly during the earthquakes NE1 and AE. Hence, due to the insignificant reduction in the base shear under different earthquakes, it might be concluded that the optimization of the TMD parameters focused on reducing the drift will not have a significant effect on the base shear of structures. Table 4 shows that the average acceleration of the structure equipped with the TMD system has increased under the FE2 and AE earthquakes by about 5\% but, for the rest of earthquakes, the parameters of TMD optimized based on drift can reduce the acceleration of the structure. Similar results have been obtained for the average displacement of the structure controlled with the TMD system. In fact, for the FE2, NE3 earthquakes, the average displacement of the controlled structure has increased while this parameter has decreased for other earthquakes. It should be noted that the negative and positive signs in Table 4 show the decrease and increase in the average reduction, respectively. In other words, the positive value shows that the parameter is reduced, and the negative value shows that it is increased.

The maximum drift ratio of all stories and the roof displacement time history of the structure are depicted in Figures 6 and 7 with and without the TMD system subjected to the near- and far-field earthquakes. It is clear from the table that the maximum drift ratio of the stories has been reduced for all earthquakes. It is also observed that the roof displacement has increased for some earthquakes (e.g., FE2, and NE3). The controlled structure has been vibrated about a new plastic axis subjected to 
these earthquakes, and the non-elastic deformation of the structure has increased. This indicates that the drift-optimized TMD system is unable to improve the seismic performance of the structure for some earthquakes.

Table 4. The average reduction in the structural responses.

\begin{tabular}{ccccc}
\hline \multirow{2}{*}{ Earthquake } & \multicolumn{4}{c}{ Average Reduction (\%) } \\
\cline { 2 - 5 } & Displacement & Drift & Acceleration & Base Shear \\
\hline FE1 & 5.78 & 5.02 & 8.10 & 2.61 \\
FE2 & -20.56 & 25.08 & -5.25 & 0.81 \\
FE3 & 11.14 & 6.53 & 10.06 & 2.75 \\
NE1 & 14.81 & 10.96 & 3.15 & -2.49 \\
NE2 & 12.26 & 4.18 & 9.03 & 0.65 \\
NE3 & -31.34 & 42.92 & 19.69 & 3.49 \\
AE & 31.55 & 19.42 & -5.23 & -1.12 \\
\hline
\end{tabular}
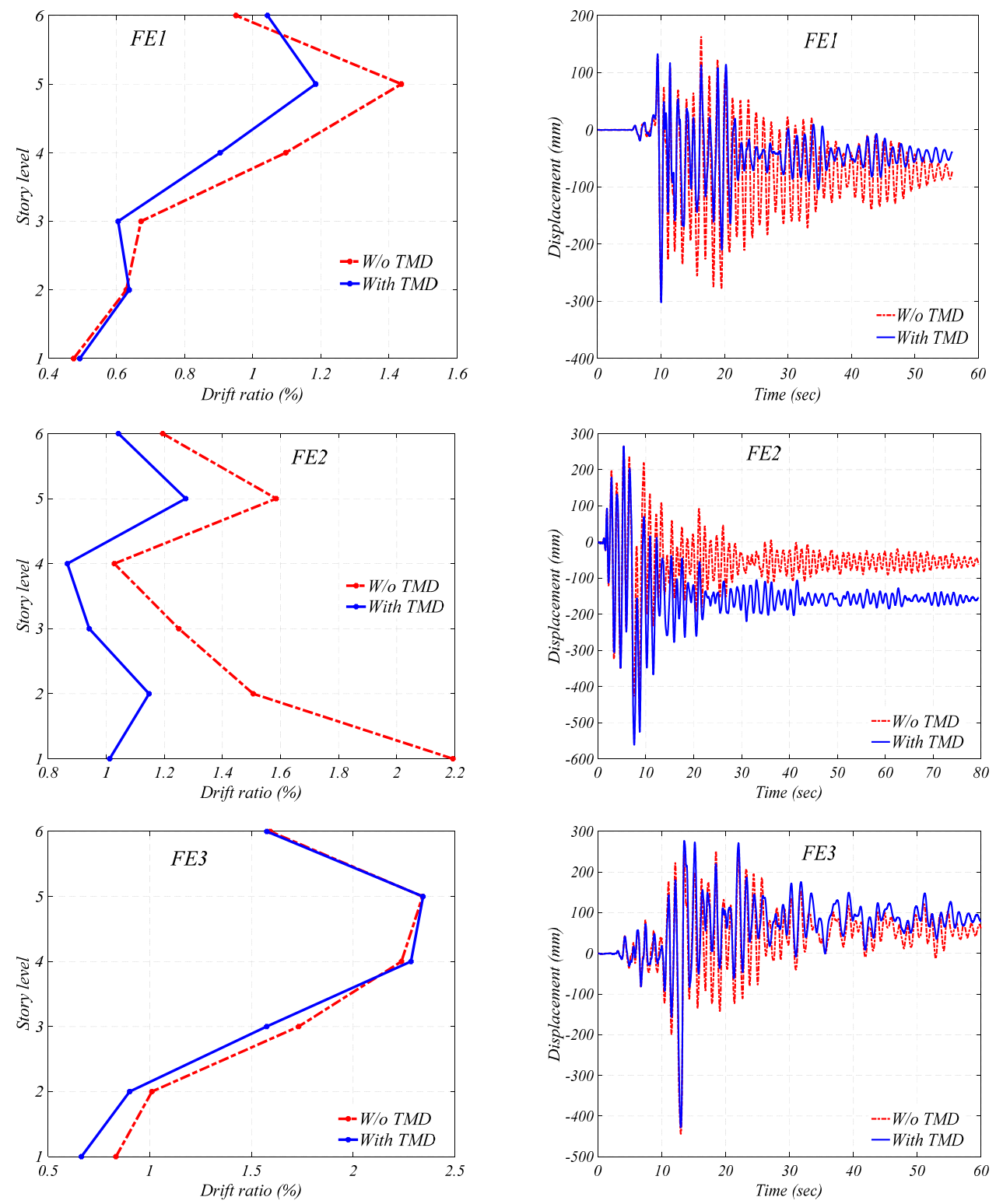

Figure 6. Drift ratios of the stories and the time history of the displacement of the roof in the controlled and uncontrolled structure subjected to the far-field earthquakes. 


\subsection{The Results of the Incremental Dynamic Analysis}

In this section, the parameters of the TMD system subjected to the different earthquakes are optimized based on minimizing the relative displacement criterion presented by FEMA-356 [48]. Next, the IDA analysis is used to investigate the dynamic performance of the six-story steel frame equipped with the TMD system. The IDA analysis is calculated for the maximum base shear, maximum acceleration, maximum displacement, and maximum drift ratio of the desired structure, and its curves for near- and far-field earthquakes are plotted in Figures 8-11.
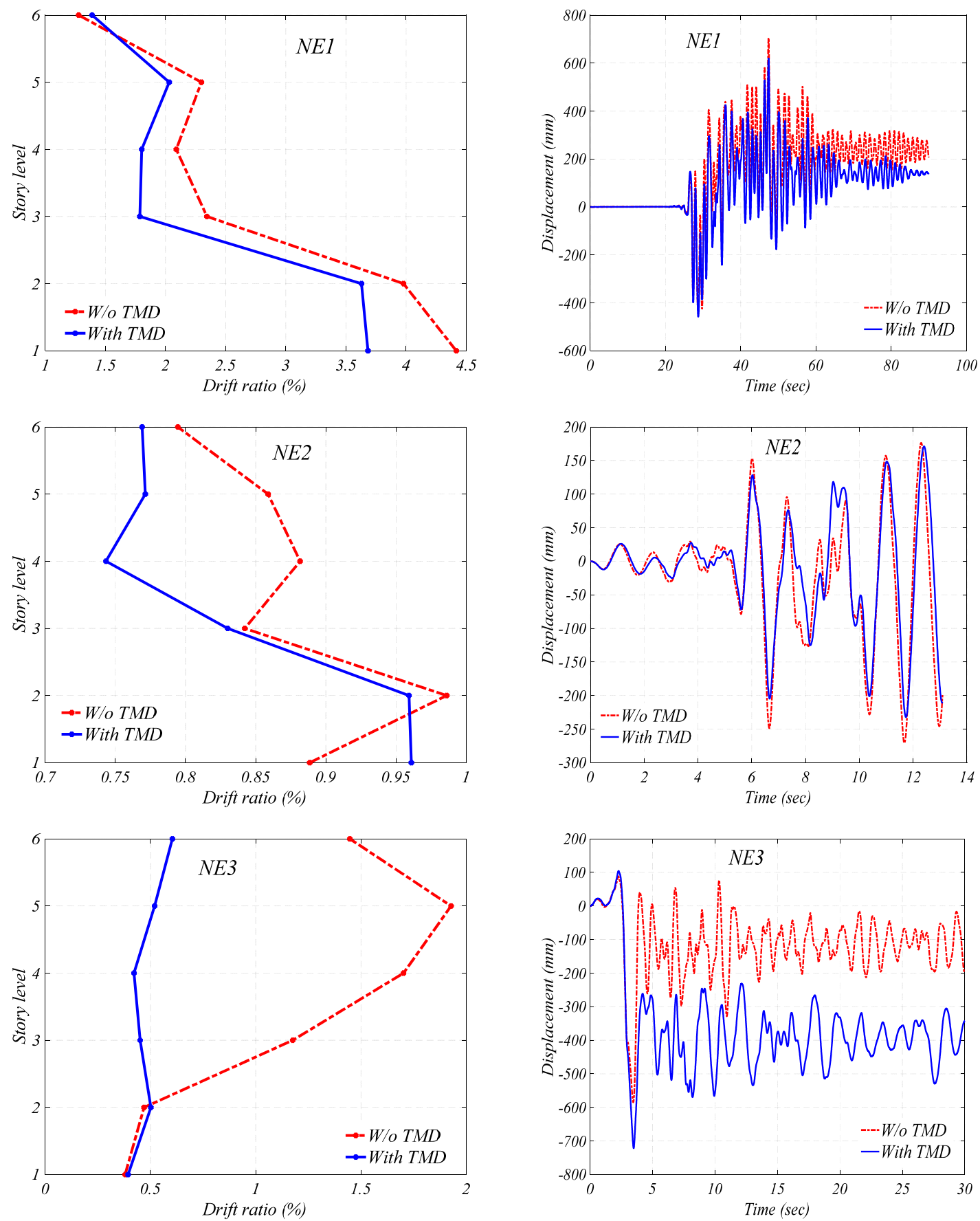

Figure 7. Drift ratios of the stories and the time history of the displacement of the roof in the controlled and uncontrolled structure subjected to the near-field earthquakes. 


\subsubsection{The Results of IDA for the Drift Ratio}

The drift ratio of the structures with and without the TMD system is shown in Figure 8. It can be concluded that the maximum drift ratio of all stories has been decreased for the structure controlled with the TMD system subjected to the FE1, NE1, and NE2 earthquakes. The drift ratio has increased for the FE2 earthquake with PGA equal to $0.9 \mathrm{~g}$ and $1 \mathrm{~g}$. Additionally, the maximum drift ratio of the structure has increased under the FE3 earthquake in the range of $0.6 \mathrm{~g} \leq \mathrm{PGA} \leq 0.9 \mathrm{~g}$. A disturbance has taken place for the NE3 earthquake in the range of $0.7 \mathrm{~g} \leq \mathrm{PGA} \leq 0.9 \mathrm{~g}$. Therefore, it might be concluded that the TMD parameters should be evaluated for PGA values larger than $0.5 \mathrm{~g}$ in controlling the drift ratio.
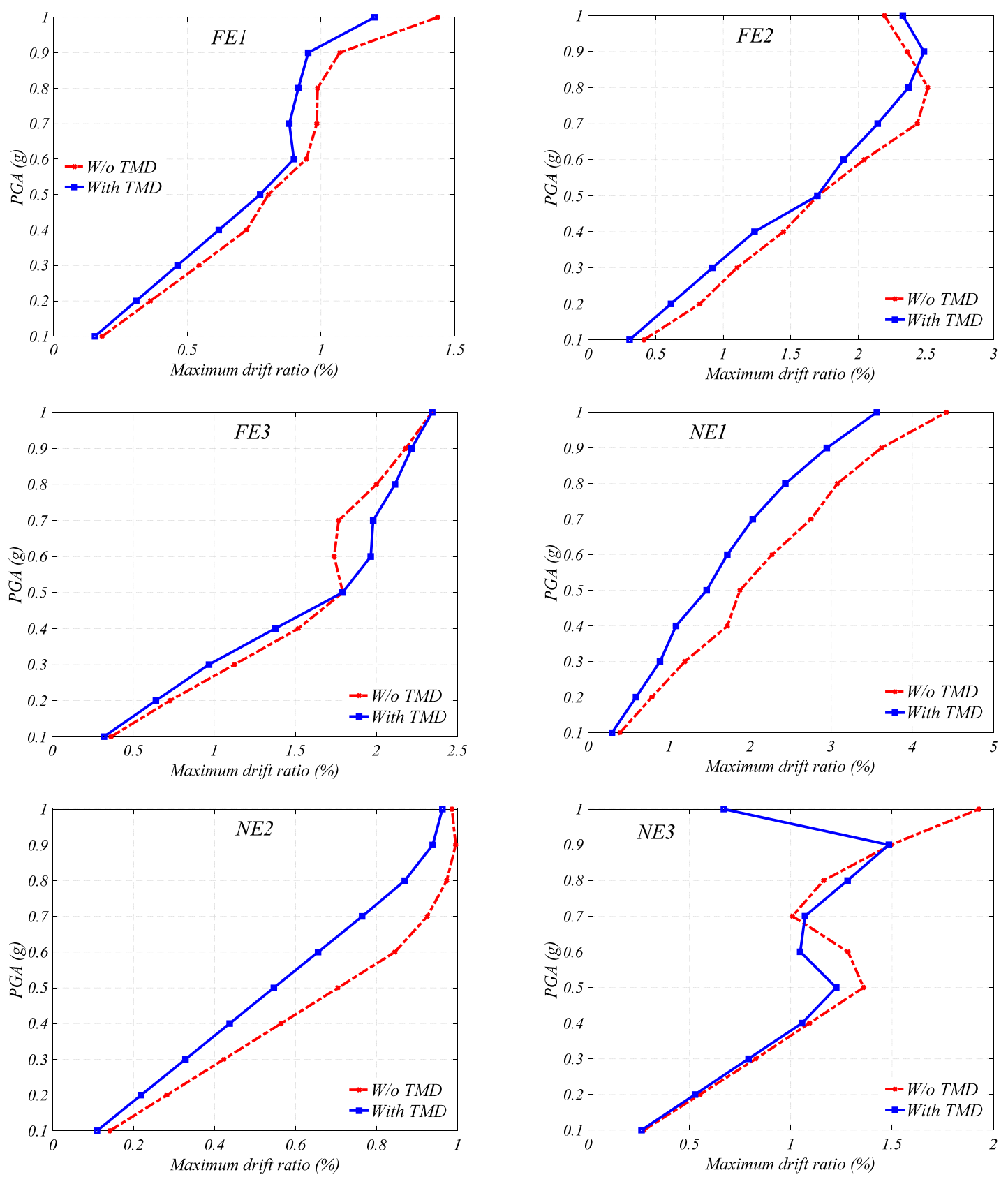

Figure 8. Maximum drift ratio of the frame subjected to different far- and near-field earthquakes. 


\subsubsection{The Results of IDA for the Maximum Displacement}

The maximum displacements of the structures subjected to different earthquakes are presented in Figure 9. This figure shows that the maximum displacement of the structure has increased subjected to the FE3 earthquake in the range of $0.6 \mathrm{~g} \leq \mathrm{PGA} \leq 0.9 \mathrm{~g}$. Therefore, it could be concluded that the optimized TMD based on the reduction of the drift ratio can reduce the maximum displacement of the structure. Additionally, it has to be noticed that the TMD parameters should be evaluated for PGA values larger than $0.5 \mathrm{~g}$ in controlling the maximum displacement.
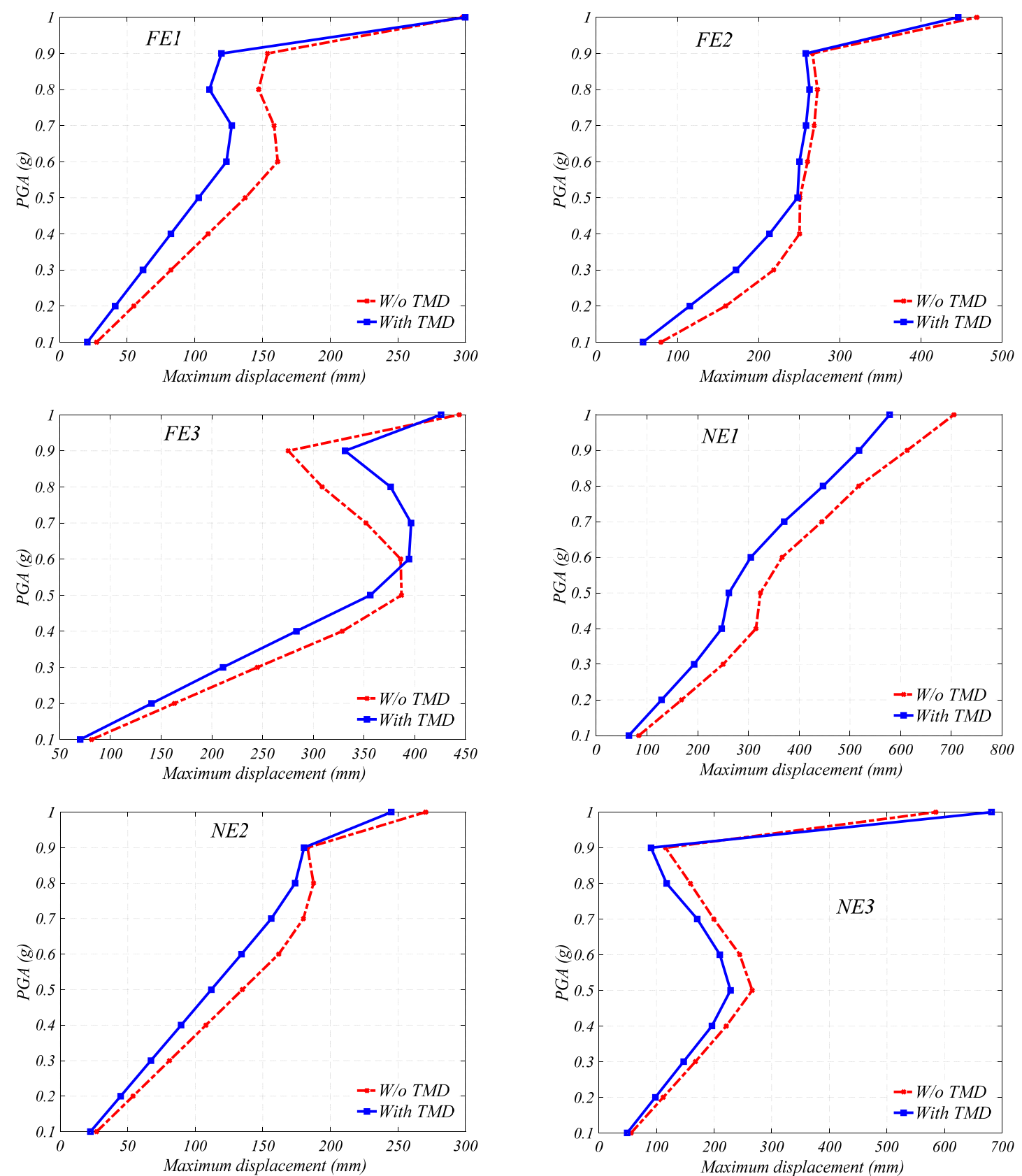

Figure 9. The maximum displacement of the frame subjected to the different far- and near-field earthquakes.

\subsubsection{The Results of IDA for the Maximum Base Shear}

Figure 10 shows the performance of the controlled and uncontrolled structures based on the base shear. As it can be seen from the figure, for all the selected earthquakes and PGA values equal or less 
than $0.5 \mathrm{~g}$, the maximum base shear of the controlled structure has decreased. Additionally, the base shear has not changed for PGA larger than $0.5 \mathrm{~g}$. Therefore, it could be concluded that the optimized TMD system based on minimizing the drift ratio does not have any particular effect on the base shear for PGA values larger than $0.5 \mathrm{~g}$.
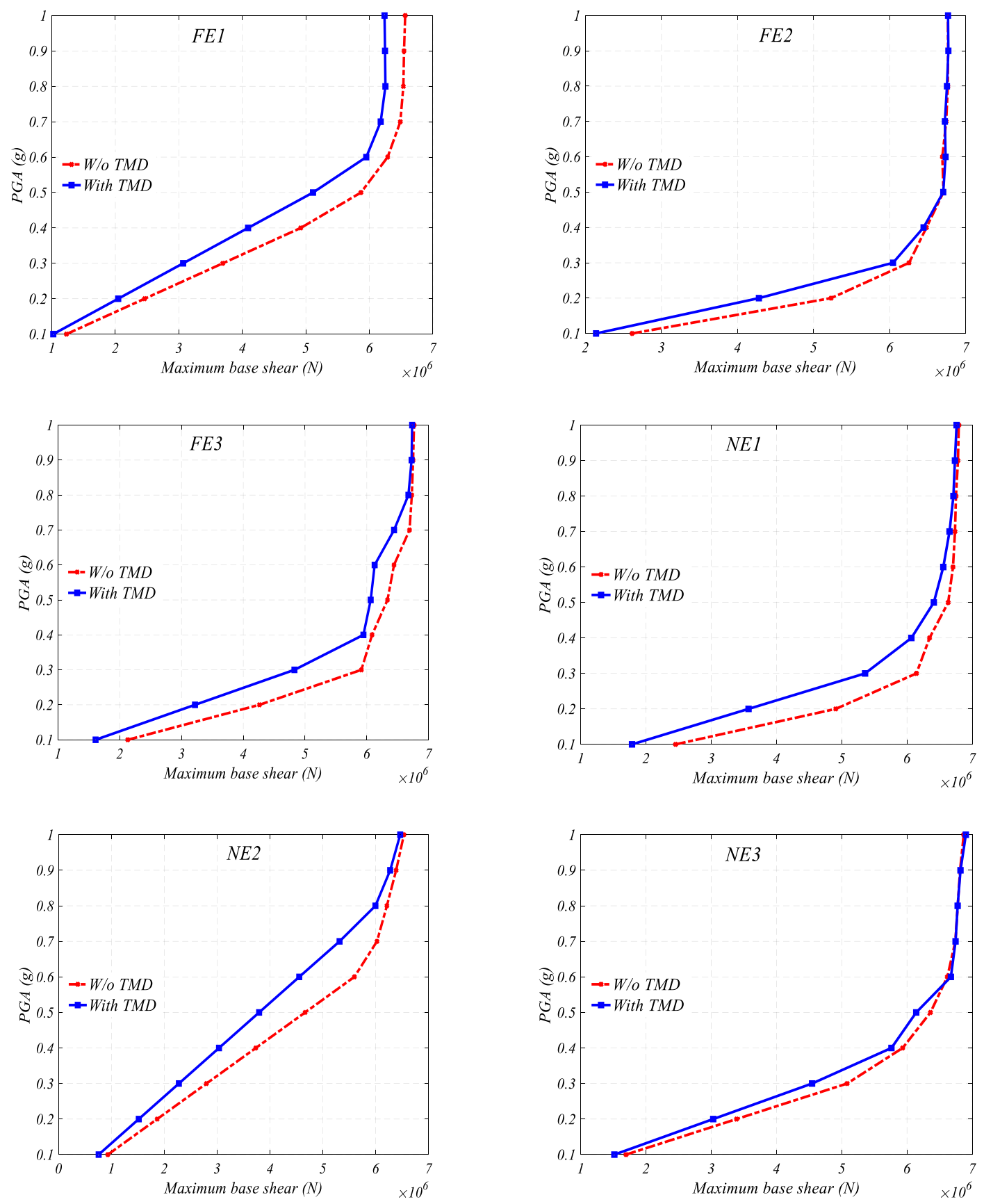

Figure 10. Maximum base shear of the frame subjected to different far- and near-field earthquakes.

7.3.4. The Results of IDA for the Maximum Acceleration of the Structure

A comparison between the results for the maximum acceleration is shown in Figure 11. It can be concluded that the performance of the structure equipped with the optimized TMD system has been improved in minimizing the maximum acceleration of the structure subjected to the FE1, NE1, and NE2 earthquakes. The maximum acceleration of the structure has increased in the range of $0.8 \mathrm{~g} \leq \mathrm{PGA} \leq 1.0 \mathrm{~g}$ under the FE2 earthquake. Besides, an increase in the acceleration response has 
occurred for the FE3 earthquake when PGA is smaller than $0.5 \mathrm{~g}$. Therefore, the performance of the controlled structure subjected to the NE3 earthquake is different in comparison to the structure subjected to other earthquakes. An increase in the maximum acceleration can be seen for the PGA equal to $0.9 \mathrm{~g}$, while a sharp decrease has occurred for the PGA equal to $1.0 \mathrm{~g}$. Therefore, it could be concluded again that the TMD parameters should be evaluated for the PGA values larger than $0.5 \mathrm{~g}$ in controlling the maximum acceleration.
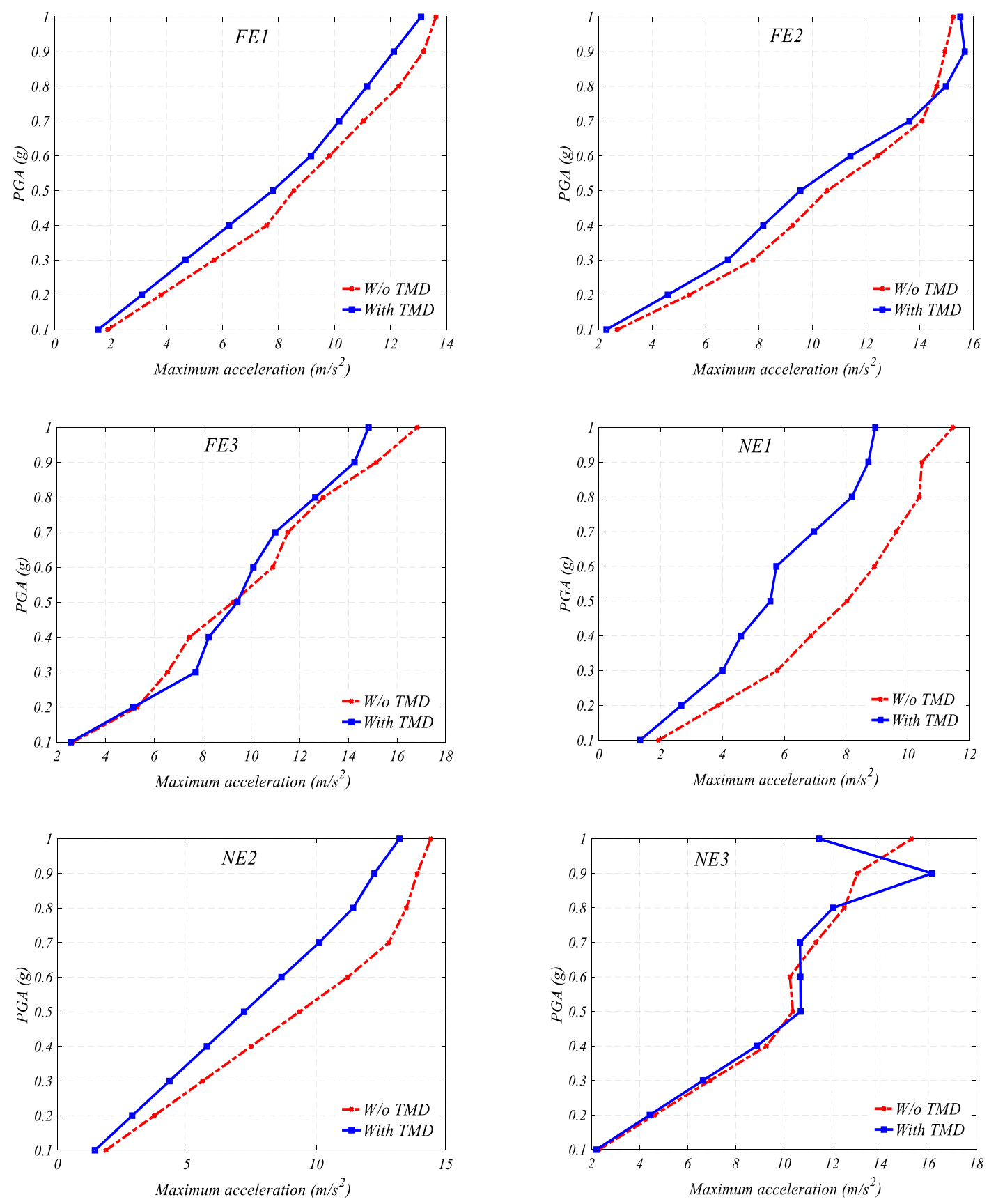

Figure 11. Maximum acceleration of the frame subjected to the different far- and near-field earthquakes. 


\subsection{The Results for the Artificial Earthquake}

7.4.1. Seismic Performance of the Controlled and Uncontrolled Structures Exposed to the Artificial Earthquake

Figure 12 presents the responses of the controlled and uncontrolled structures (i.e., drift ratio, maximum displacement, maximum base shear, and the maximum acceleration) exposed to the artificial earthquake. The figure indicates that the TMD system optimized based on the drift ratio can reduce all structural responses, except for the maximum acceleration of the structure. The optimized TMD system has also controlled the maximum acceleration of the fifth and sixth stories, but it has increased this value for the lower stories.
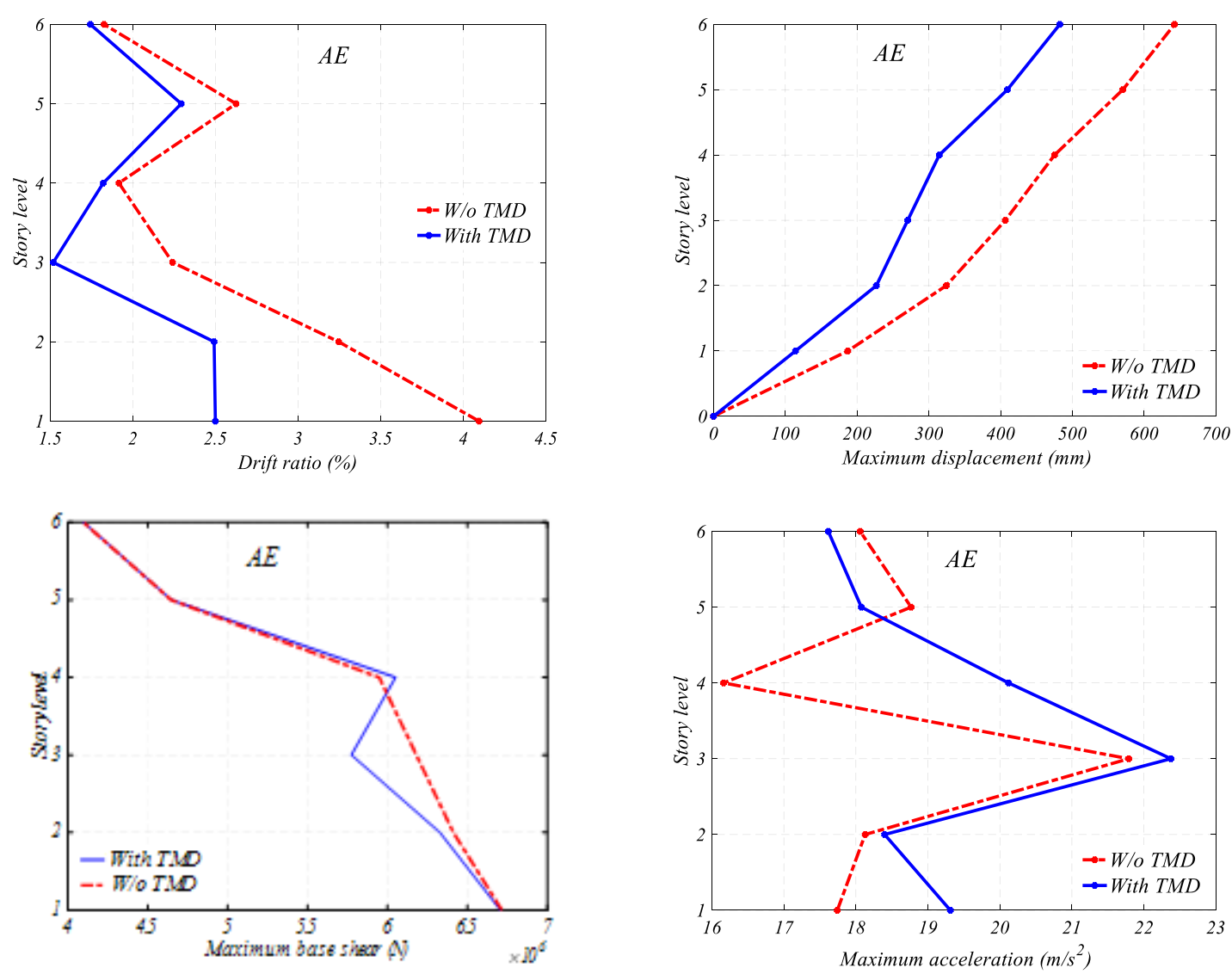

Figure 12. Maximum drift ratio, displacement, base shear, and acceleration of the frame subjected to the artificial earthquake.

7.4.2. IDA for the Dynamic Performance of the Controlled and Uncontrolled Structures Exposed to the Artificial Earthquake

The results of IDA for the structure subjected to artificial earthquakes are shown in Figure 13. The performance of the controlled structure shows an increase in the maximum acceleration values in the range of $0.7 \mathrm{~g} \leq \mathrm{PGA} \leq 0.8 \mathrm{~g}$. The maximum acceleration of the structure has decreased for other PGA values. Moreover, the value of base shear has decreased for PGA smaller than $0.5 \mathrm{~g}$ and remained constant for PGA larger than $0.5 \mathrm{~g}$. Additionally, the results show that the performance of the structure has improved for the maximum displacement and drift ratio. 

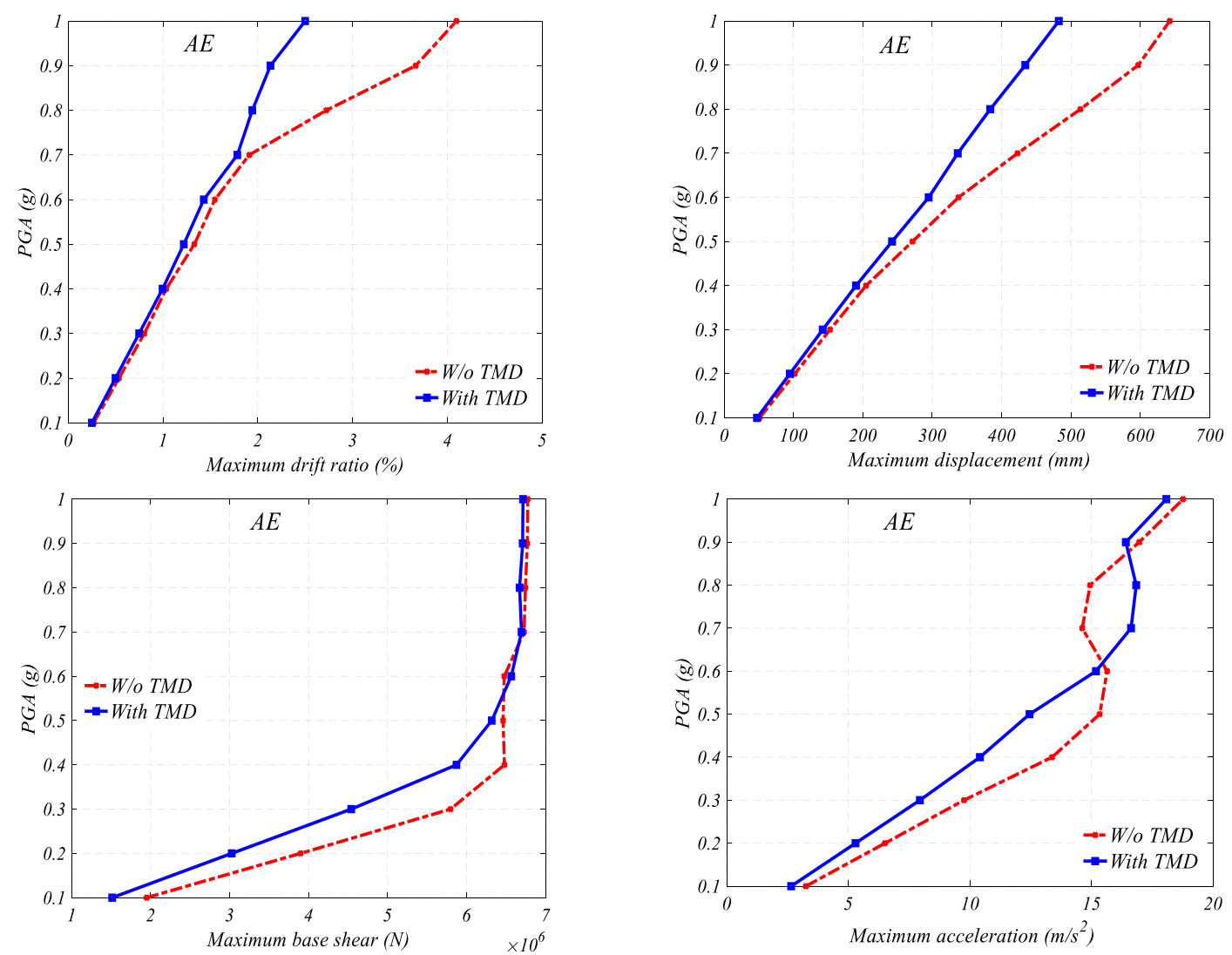

Figure 13. Results of Incremental Dynamic Analysis (IDA) analysis for the frame subjected to the artificial earthquake.

7.4.3. Investigation of the Performance Level of the Structure Subjected to the Artificial Earthquake

The performance levels of the structure subjected to the artificial earthquake, based on the FEMA-356 [48], are presented in Figure 14. Based on FEMA-356, the maximum drift ratios of the controlled and uncontrolled structures have been categorized in the figure as:

1. Immediate Occupancy $\leq 0.7 \%$;

2. $0.7 \% \leq$ Life Safety $\leq 2.5 \%$;

3. $2.5 \% \leq$ Collapse Prevention $\leq 5 \%$.

As it can be observed from Figure 14, the six-story steel moment-resisting frame without TMD system has entered into the collapse prevention level for PGA larger than $0.8 \mathrm{~g}$, but the performance level of the structure controlled with the TMD system has remained in the life safety range. Therefore, results indicate that the optimization of the TMD parameters to minimize the maximum drift ratio smaller than $2.5 \%$ substantially improve the seismic performance of the structure subjected to the artificial earthquake. It leads to a delay in the fracture of the bending connections (see FEMA-356 [48]), and it can help the beams and columns to sustain distortion. 


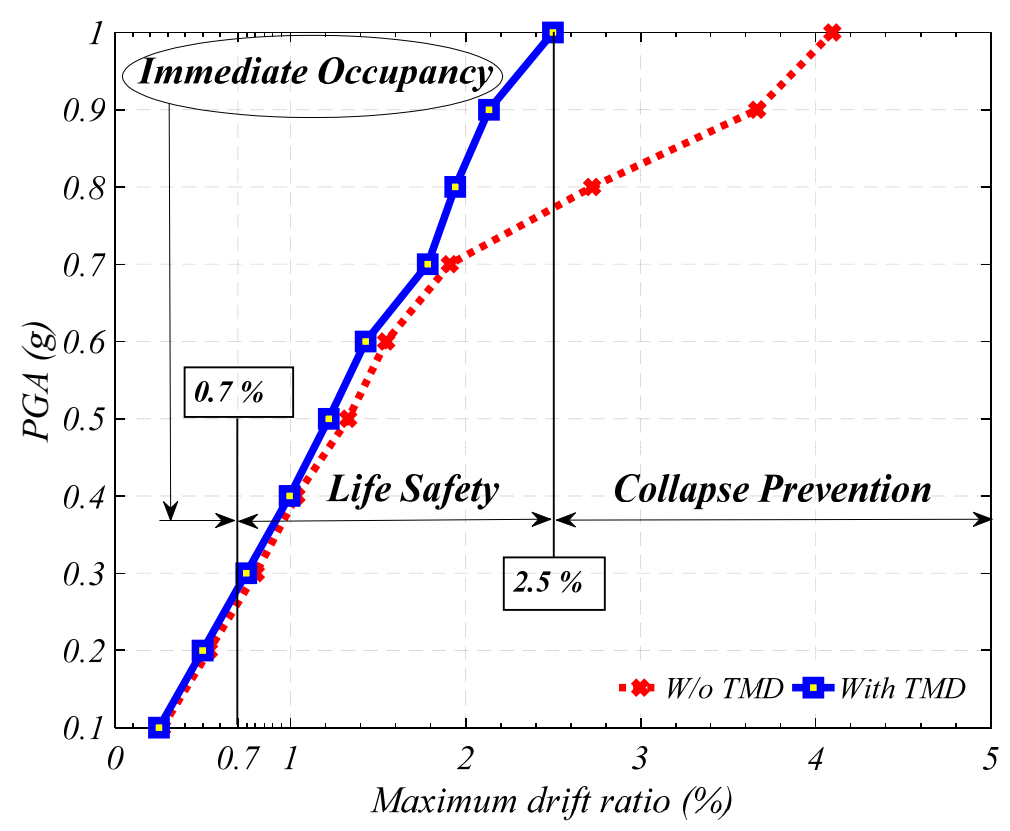

Figure 14. The performance level of the frame subjected to the artificial earthquake.

Besides, to evaluate the capability of the method presented in this paper, the six-story steel moment-resisting frame structure is considered. For this purpose, two other objective functions (see Equation (25)) are considered, and the optimal values of the TMD system are computed under the artificial earthquake. Table 5 shows the optimal values of the TMD system for different objective functions. It should be noted that the constraints and upper and lower bounds are considered as in Equation (1) and Ref. [46].

Find: $M_{d}, K_{d}, C_{d}$

Minimize : $\max \left(\frac{\max \left|d r i f t_{i}\right|_{\text {with TMD }}}{\max \mid \text { drifti }\left.\right|_{\text {without TMD }}}\right) \times 100, \quad i=1,2,3, \ldots$,

Minimize : $\max \left(\frac{\max \left|A c c_{\text {roof }}\right|_{\text {with } T M D}}{\max \left|A c c_{\text {roof }}\right|_{\text {without TMD }}}\right) \times 100, \quad i=1,2,3, \ldots, n \quad$ (O .F 2)

Minimize : $\max \left(\frac{\max \mid \text { Disp roof }_{\text {with TMD }}}{\max \mid \text { Disp roof }_{\text {without TMD }}}\right) \times 100, \quad i=1,2,3, \ldots, n$

where O.F., Acc roof, and Disp $p_{\text {roof }}$ show the objective function, roof acceleration, and displacement, respectively. The last-second objective functions are usually used by researchers to optimize the parameters of vibration control systems $[18,34,37,40]$. Additionally, the computational workload, in the form of required running time, for each objective function is presented in Table 5 . The calculations have been run on a computer with a 64-bit operating system and CPU Intel(R) Core(TM) i3-4170 CPU 3.70 GHz with 4 GB RAM.

Table 5. Optimum parameters and required running time achieved for the TMD subjected the artificial earthquake for different objective functions.

\begin{tabular}{|c|c|c|c|c|}
\hline O.F & $K_{t m d}(\mathrm{~N} / \mathrm{mm})$ & $C_{t m d}(\mathrm{~N} \cdot \mathrm{s} / \mathrm{mm})$ & $M_{t m d}\left(\mathrm{~N} \cdot \mathrm{s}^{2} / \mathrm{mm}\right)$ & $\underset{\text { (s) }}{\text { Required Running Time }}$ \\
\hline O.F 1 & 405.47 & 935.66 & 180 & 997.854 \\
\hline O.F. 2 & 211.021 & 1130.6 & 122.87 & 865.528 \\
\hline O.F. 3 & 250.025 & 749.317 & 163.156 & 1114.548 \\
\hline
\end{tabular}


It can be seen from Table 5 that the required running time for O.F. 2 is shorter than for two other objective functions. Moreover, the computational workload of the proposed objective function (O.F 1) is between those of the two traditional objective functions (O.F. 2 and O.F. 3).

Table 6 presents the maximum responses of the controlled and uncontrolled structures subjected to the artificial earthquake for different objective functions. The maximum roof displacement, roof acceleration, and drift ratio for the uncontrolled structures are $0.642 \mathrm{~m}, 18.06 \mathrm{~m} / \mathrm{s}^{2}$, and $4.09 \%$, respectively. Table 6 shows that O.F 1 has the best performance between all studied objective functions in reducing the maximum responses of the structure and therefore improving the seismic behavior of the structures.

Table 6. Maximum responses of the controlled structure subjected to the artificial earthquake for different objective functions.

\begin{tabular}{cccc}
\hline $\begin{array}{c}\text { Objective } \\
\text { Function }\end{array}$ & $\begin{array}{c}\text { Max. } \\
\text { Roof } \\
\text { Disp. } \\
(\mathbf{m})\end{array}$ & $\begin{array}{c}\text { Max. } \\
\text { Roof } \\
\text { Acc. } \\
\left(\mathbf{m} / \mathbf{s}^{2}\right)\end{array}$ & $\begin{array}{c}\text { Max. } \\
\text { Drift Ratio } \\
(\mathbf{\%})\end{array}$ \\
\hline O.F 1 & 0.504 & 17.74 & 2.45 \\
\hline O.F. 2 & 0.509 & 17.52 & 2.82 \\
\hline O.F. 3 & 0.515 & 17.75 & 2.61 \\
\hline
\end{tabular}

Additionally, to evaluate the capability of the method presented in this paper, the 10-story steel moment-resisting frame structure is considered here that has been studied by Wong and Johnson [64]. The mass of all stories and the damping ratio for all 10 modes are assumed to be equal to $m=218,900 \mathrm{~kg}$, and 3\%, respectively [64]. The cross-sections and lengths for the beams and columns of the structure are shown in Figure 15. The material has the yield stress equal to 248.2 MPa. Additionally, a gravity uniformly distributed load, equal to $21.89 \mathrm{kN} / \mathrm{m}$, is applied to all beams. The modulus of elasticity is considered to be equal to $200 \mathrm{GPa}$. All beam-to-column connections are considered to be rigid [64]. The first natural frequency of the 10-story steel frame is $4.19 \mathrm{rad} / \mathrm{s}$, which is equal to the results presented by Wong and Johnson in [64]. It can be seen that the differences are negligible, therefore, it confirms the accuracy of the modeling approach. Then, the optimum parameters of the TMD system are computed using WCA for the first objective function (O.F 1) subjected to the artificial earthquake, a far- and near-field earthquake. The optimal values of the TMD system are shown in Table 7.

Table 7. Optimum parameters achieved for the TMD system subjected the far-, near- and artificial earthquakes.

\begin{tabular}{|c|c|c|c|}
\hline Earthquake & $K_{t m d}(\mathrm{~N} / \mathrm{mm})$ & $C_{t m d}(\mathrm{~N} \cdot \mathrm{s} / \mathrm{mm})$ & $M_{t m d}\left(\mathrm{~N} \cdot \mathrm{s}^{2} / \mathrm{mm}\right)$ \\
\hline FFE3 & 263.34 & 130.87 & 91.08 \\
\hline NE2 & 170.78 & 89.06 & 59.28 \\
\hline $\mathrm{AE}$ & 84.21 & 2000 & 131.59 \\
\hline
\end{tabular}

Finally, for the controlled structure using the optimum parameters presented in Table 7, the IDA analysis is run. Figures 16-18 show the IDA curves for the responses of the controlled structure in comparison with the uncontrolled one.

Figure 16 shows that the performance of the controlled structure shows a decrease in the maximum acceleration, maximum displacement, and drift ratio for all regions of PGA; but, the maximum base shear has been increased in the range of $0.5 \mathrm{~g} \leq \mathrm{PGA} \leq 0.6 \mathrm{~g}$. It can also be seen from Figure 17 that the performance of the controlled structure shows a decrease in the maximum displacement in the range of PGA $\leq 0.6 \mathrm{~g}$. The maximum acceleration of the structure has decreased for all values of PGA, except for $0.8 \mathrm{~g}$, and $1 \mathrm{~g}$. Moreover, the value of base shear has decreased for PGA smaller than $0.9 \mathrm{~g}$. Additionally, the results show that the performance of the structure has improved for the 
maximum drift ratio for the PGA smaller than $0.5 \mathrm{~g}$. Figure 18 indicates that the performance of the controlled structure shows a decrease in all regions of PGA for the maximum drift ratio, acceleration, and base shear. The maximum displacement of the structure has decreased for all values of PGA in the range of $\mathrm{PGA} \leq 0.8 \mathrm{~g}$. Therefore, the results show that the performance of the structure has improved significantly.

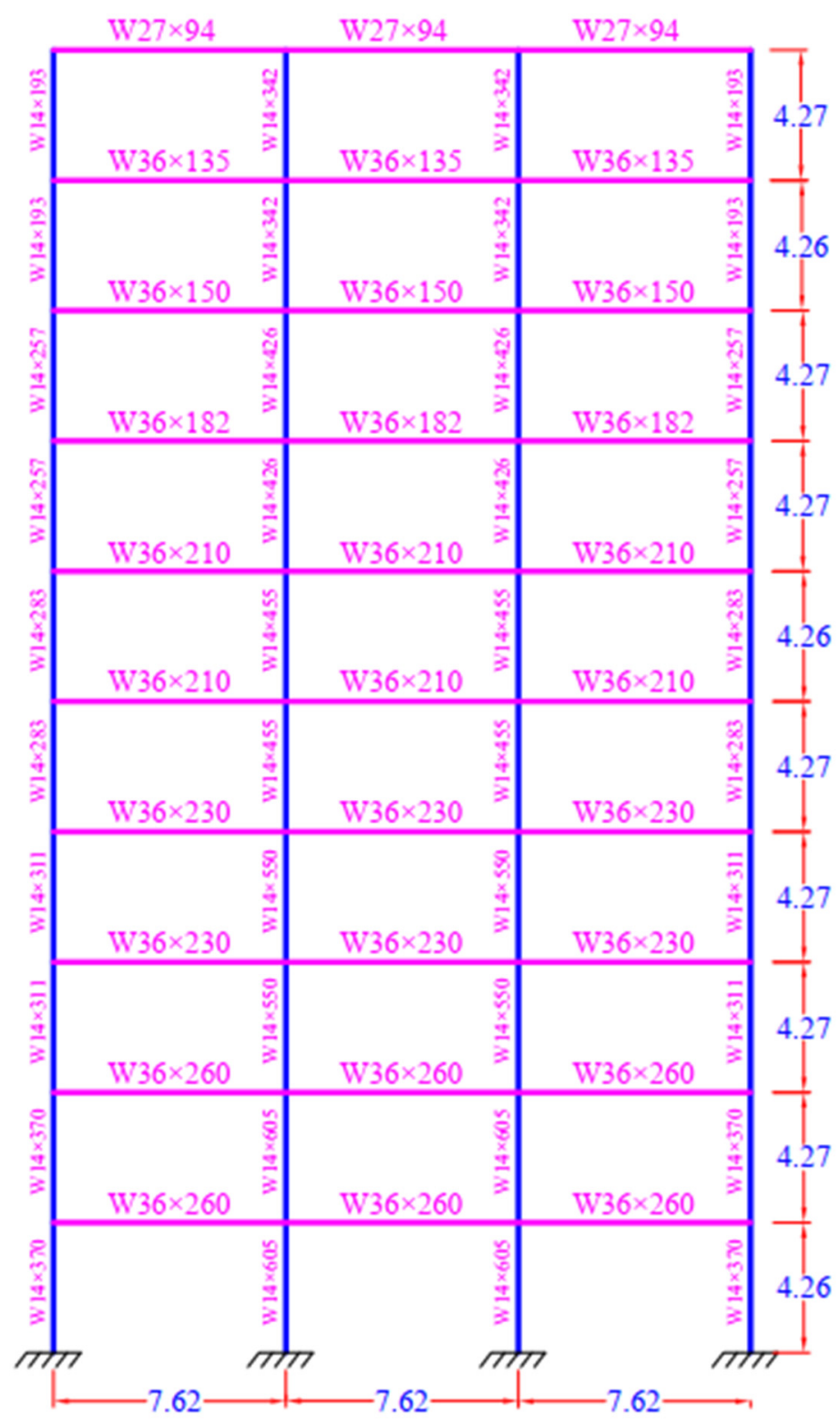

Figure 15. Ten-story steel moment-resisting frame. 

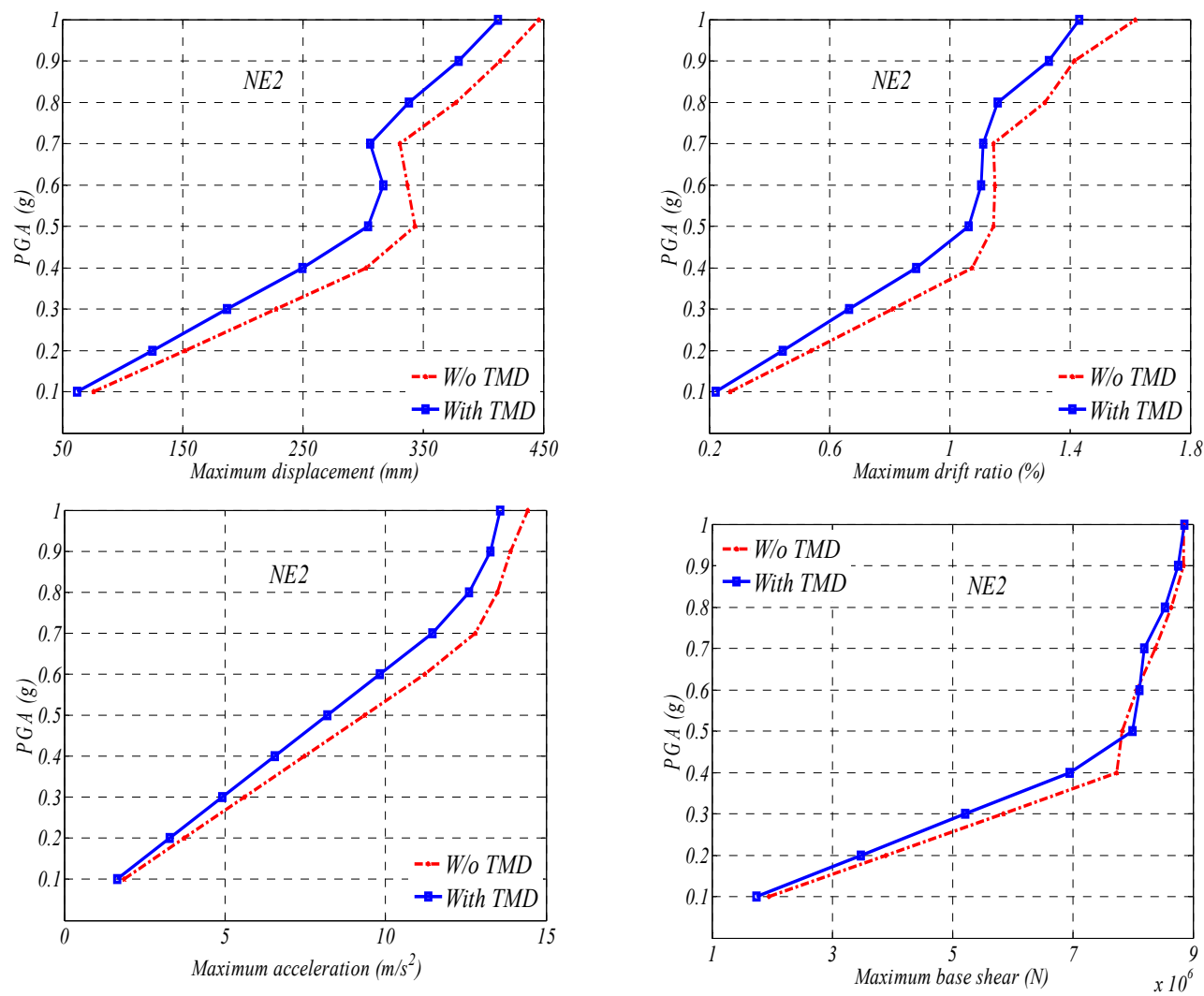

Figure 16. Results of IDA analysis for the frame subjected to a near-field earthquake (Gazli earthquake).
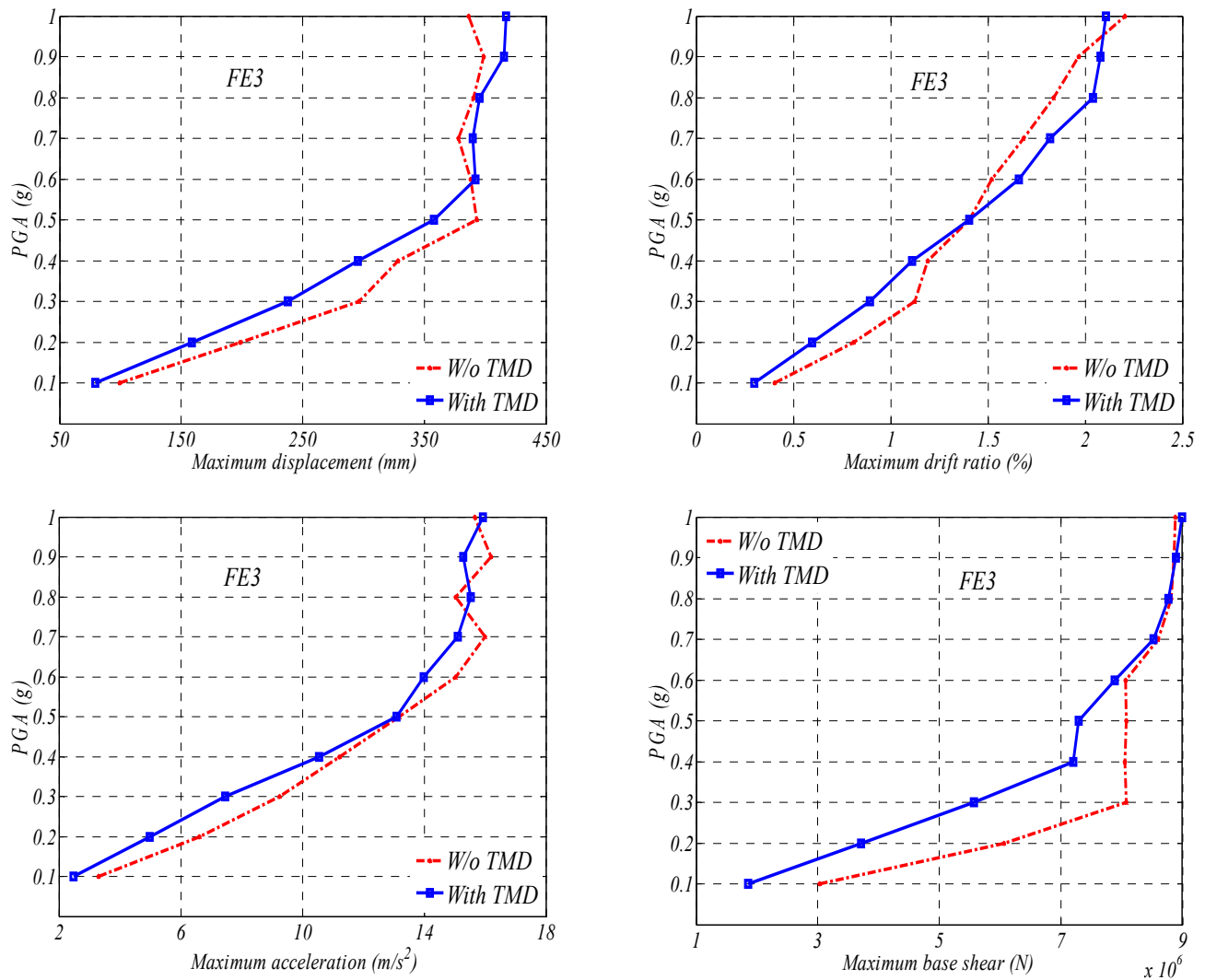

Figure 17. Results of IDA analysis for the frame subjected to a far-field earthquake (Superstition earthquake). 

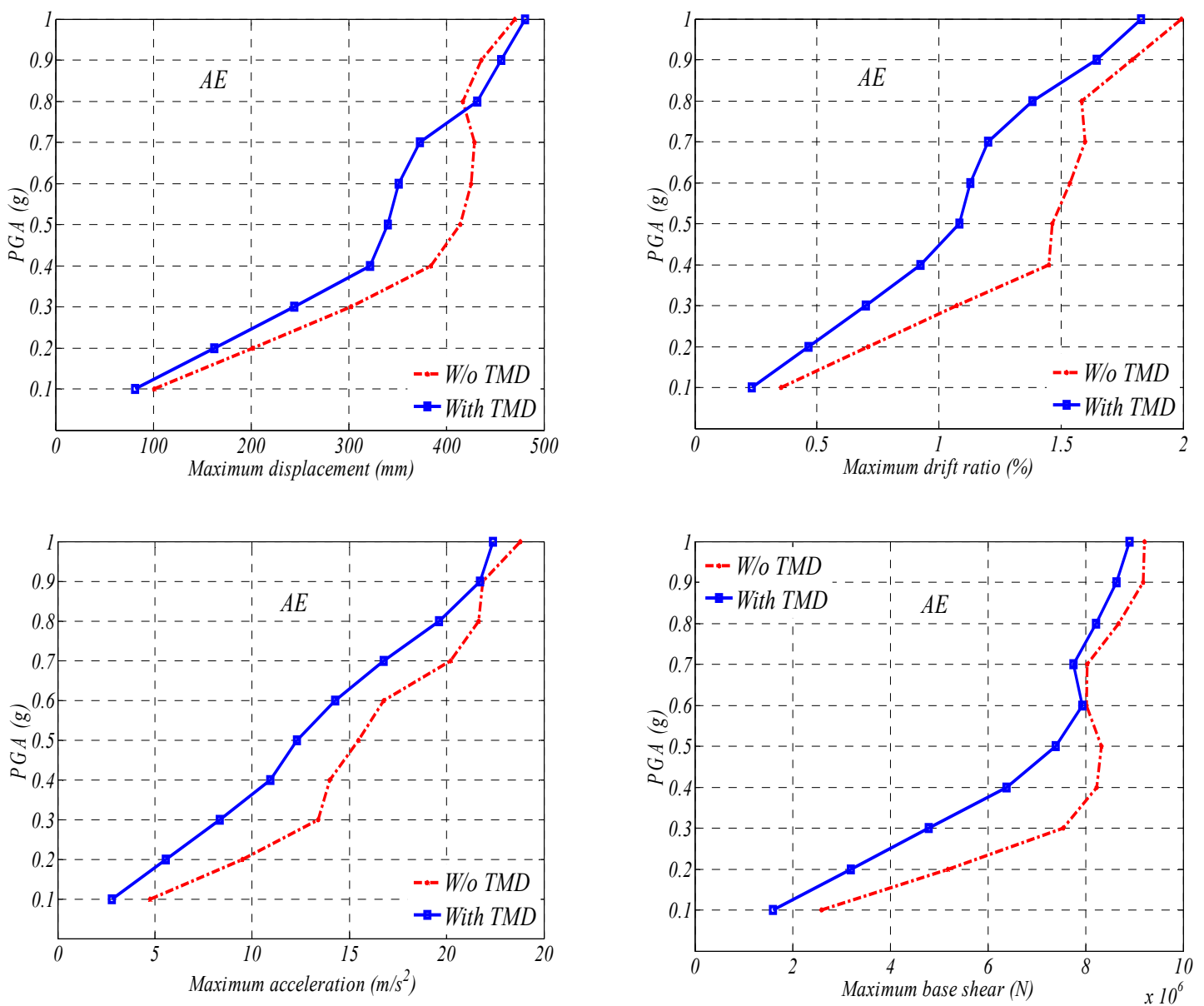

Figure 18. Results of IDA analysis for the frame subjected to the artificial earthquake.

\section{Conclusions}

The performance-based design of the steel structure controlled with the TMD system has been investigated in this paper. All studied earthquakes have been scaled in such a way that all have had the PGA value equal to $1 \mathrm{~g}$. Then, the optimum parameters of the TMD system have been calculated using a meta-heuristic algorithm (i.e., WCA) focused on minimizing the maximum drift ratio of the stories based on the FEMA-356 subjected to the scaled earthquakes. For this purpose, two different frame buildings (i.e., a six-story and a 10-story moment-resisting frame) have been considered and modeled with the OpenSees software. The optimum parameters of the TMD system have been computed subjected to the scaled earthquakes. Then, PGA has been changed in the range of $0.1 \mathrm{~g}$ to $1 \mathrm{~g}$ in IDA, and the responses of the controlled structure have been examined. The results of the study show that the base shear decreases for the PGA value smaller than $0.5 \mathrm{~g}$ under all earthquakes studied. At the same time, for all records with PGA larger than $0.5 \mathrm{~g}$, the TMD system does not make any considerable reduction in the base shear value of the controlled structure. This sentence is correct for the maximum drift ratio. Finally, the responses of controlled structure (i.e., the maximum acceleration and displacement) have almost decreased for all regions of PGA.

Moreover, the results of the investigation show that optimizing the TMD parameters, based on minimizing the drift ratio, decreases the structural displacement, and improves the seismic behavior of the structure based on FEMA-356. The results also indicate that the response of the controlled and uncontrolled structure (e.g., drift ratio, maximum displacement, maximum base shear) is reduced during the artificial earthquake. Additionally, the optimization of the TMD parameters, to keep the maximum drift ratio smaller than $2.5 \%$, improves the seismic performance of the structure subjected to 
the artificial earthquake. It leads to a delay in the fracture of the bending connections, and it can help the beams and columns to sustain distortion.

Finally, a comparison between the traditional objective functions and the proposed objective function (i.e., the maximum drift ratio of less than $2.5 \%$ ) has been presented. The results show that the optimum parameters of the TMD system based on the proposed objective function have a better performance in reducing the structural responses in comparison with the other previously used objective functions.

Author Contributions: Conceptualization, M.D., R.K., and H.H.; methodology, M.D., R.K., H.H., A.J.-G., and R.J.; software, M.D., R.K., and H.H.; validation, M.D., R.K., H.H., A.J.-G., and R.J.; formal analysis, M.D., R.K., and H.H.; investigation, M.D. and R.K.; writing—original draft preparation, M.D., R.K., and H.H.; writing一review and editing, A.J.-G. and R.J. All authors have read and agreed to the published version of the manuscript.

Funding: This research received no external funding.

Conflicts of Interest: The authors declare no conflicts of interest.

\section{References}

1. Elwardany, H.; Seleemah, A.; Jankowski, R. Seismic pounding behavior of multi-story buildings in series considering the effect of infill panels. Eng. Struct. 2017, 144, 139-150. [CrossRef]

2. Elwardany, H.; Seleemah, A.; Jankowski, R.; El-Khoriby, S. Influence of soil-structure interaction on seismic pounding between steel frame buildings considering the effect of infill panels. Bull. Earthq. Eng. 2019, 17, 6165-6202. [CrossRef]

3. Jankowski, R. Pounding between superstructure segments in multi-supported elevated bridge with three-span continuous deck under 3D non-uniform earthquake excitation. J. Earthq. Tsunami 2015, 9, 1550012. [CrossRef]

4. Sołtysik, B.; Jankowski, R. Non-linear strain rate analysis of earthquake-induced pounding between steel buildings. Int. J. Earth Sci. Eng. 2013, 6, 429-433.

5. Kamgar, R.; Rahgozar, R. Determination of optimum location for flexible outrigger systems in non-uniform tall buildings using energy method. Int. J. Optim. Civ. Eng. 2015, 5, 433-444.

6. Tavakoli, R.; Kamgar, R.; Rahgozar, R. The best location of belt truss system in tall buildings using multiple criteria subjected to blast loading. Civ. Eng. J. 2018, 5, 1338-1353. [CrossRef]

7. Tavakoli, R.; Kamgar, R.; Rahgozar, R. Seismic performance of outrigger-belt truss system considering soil-structure interaction. Int. J. Adv. Struc. Eng. 2019, 11, 45-54. [CrossRef]

8. Kamgar, R.; Shojaee, S.; Rahgozar, R. Rehabilitation of tall buildings by active control system subjected to critical seismic excitation. Asi. J. Civ. Eng. 2015, 16, 819-833.

9. Chung, L.L.; Wu, L.Y.; Huang, H.H.; Chang, C.H.; Lien, K.H. Optimal design theories of tuned mass dampers with nonlinear viscous damping. Earthq. Eng. Eng. Vib. 2009, 8, 547-560. [CrossRef]

10. Fei, Z.; Jinting, W.; Feng, J.; Liqiao, L. Control performance comparison between tuned liquid damper and tuned liquid column damper using real-time hybrid simulation. Earthq. Eng. Eng. Vib. 2019, 18, 695-701. [CrossRef]

11. Housner, G.W.; Bergman, L.A.; Caughey, T.K.; Chassiakos, A.G.; Claus, R.O.; Masri, S.F.; Skelton, R.E.; Soong, T.T.; Spencer, B.F.; Yao, J.T.P. Structural control: Past, present, and future. J. Eng. Mech. 1997, 123, 897-971. [CrossRef]

12. Kamgar, R.; Askari Dolatabad, Y.; Babadaei Samani, M.R. Seismic optimization of steel shear wall using shape memory alloy. Int. J. Optim. Civ. Eng. 2019, 9, 671-687.

13. Lasowicz, N.; Kwiecień, A.; Jankowski, R. Experimental study on the effectiveness of polymer damper in damage reduction of temporary steel grandstand. J. Phys. Conf. Ser. 2015, 628, 012051. [CrossRef]

14. Falborski, T.; Jankowski, R. Experimental study on effectiveness of a prototype seismic isolation system made of polymeric bearings. Appl. Sci. 2017, 7, 808. [CrossRef]

15. Miari, M.; Choong, K.K.; Jankowski, R. Seismic pounding between adjacent buildings: Identification of parameters, soil interaction issues and mitigation measures. Soil Dyn. Earthq. Eng. 2019, 121, 135-150. [CrossRef]

16. Kamgar, R.; Khatibinia, M.; Khatibinia, M. Optimization criteria for design of tuned mass dampers including soil-structure interaction effect. Int. J. Optim. Civ. Eng. 2019, 9, 213-232. 
17. Kamgar, R.; Samea, P.; Khatibinia, M. Optimizing parameters of tuned mass damper subjected to critical earthquake. Struct. Des. Tall Spec. Build. 2018, 27, 1460. [CrossRef]

18. Kaveh, A.; Mohammadi, S.; Hosseini, O.K.; Keyhani, A.; Kalatjari, V.R. Optimum parameters of tuned mass dampers for seismic applications using charged system search. Iran. J. Sci. Technol. Trans. Civil Eng. 2015, 39, 21.

19. Khatibinia, M.; Gholami, H.; Kamgar, R. Optimal design of tuned mass dampers subjected to continuous stationary critical excitation. Int. J. Dyn. Control 2018, 6, 1094-1104. [CrossRef]

20. Kamgar, R.; Gholami, F.; Zarif Sanayei, H.R.; Heidarzadeh, H. Modified tuned liquid dampers for seismic protection of buildings considering soil-structure interaction effects. Iran. J. Sci. Technol. Trans. Civ. Eng. 2020, 44, 339-354. [CrossRef]

21. Soong, T.T.; Dargush, G.F. Passive Energy Dissipation Systems in Structural Engineering; Wiley: Hoboken, NJ, USA, 1997.

22. Mualla, I.H.; Belev, B. Performance of steel frames with a new friction damper device under earthquake excitation. Eng. Struc. 2002, 24, 365-371. [CrossRef]

23. Jarrahi, H.; Asadi, A.; Khatibinia, M.; Etedali, S. Optimal design of rotational friction dampers for improving seismic performance of inelastic structures. J. Buil. Eng. 2020, 27, 100960. [CrossRef]

24. Miguel, L.F.F.; Miguel, L.F.F.; Lopea, R.H. Simultaneous optimization of force and placement of friction dampers under seismic loading. Eng. Opt. 2016, 48,1-21. [CrossRef]

25. Shen, H.; Zhang, R.; Weng, D.; Ge, Q.; Wang, C.; Islam, M.M. Design method of structural retrofitting using viscous dampers based on elastic-plastic response reduction curve. Eng. Struc. 2020, 208, 109917. [CrossRef]

26. Akehashi, H.; Takewaki, I. Comparative investigation on optimal viscous damper placement for elastic-plastic MDOF structures: Transfer function amplitude for double impulse. Soil Dyn. Earth. Eng. 2020, 130105987. [CrossRef]

27. Naeem, A.; Kim, J. Seismic performance evaluation of spring viscous damper cable system. Eng. Struc. 2018, 176, 455-467. [CrossRef]

28. Wei, M.; Rui, X.; Zhu, W.; Yang, F.; Gu, L.; Zhu, H. Design, modelling and testing of a novel high-torque magnetorheological damper. Smart Mat. Struc. 2020, 29, 025024. [CrossRef]

29. Farahmand Azar, B.; Veladi, H.; Talatahari, S.; Raeesi, F. Optimal design of magnetorheological damper based on tuning Bouc-Wen model parameters using hybrid algorithm. Struc. Eng. 2020, 24, 867-878.

30. Petrini, F.; Giaralis, A.; Wang, Z. Optimal tuned mass-damper-inerter (TMDI) design in wind-excited tall buildings for occupants' comfort serviceability performance and energy harvesting. Eng. Struc. 2020, 204, 109904. [CrossRef]

31. Masnata, C.; Matteo, A.D.; Adam, C.; Pirrotta, A. Smart structures through nontraditional design of tuned mass damper inerter for higher control of base isolated systems. Mech. Res. Comm. 2020, 105, 103513. [CrossRef]

32. Love, J.S.; McNamara, K.P.; Tiat, M.J.; Haskett, T.C. Series-type pendulum tuned mass damper-tuned sloshing damper. J. Vib. Ac. 2020, 142, 011003. [CrossRef]

33. Gandomi, A.H.; Yang, X.S.; Talatahari, S.; Alavi, A.H. Metaheuristic algorithms in modeling and optimization. Metaheuristic Appl. Struct. Infrastruct. 2013, 1-24.

34. Kaveh, A.; Pirgholizadeh, S.; Khadem, H.O. Semi-active tuned mass damper performance with optimized fuzzy controller using CSS algorithm. Asian J. Civil Eng. 2015, 16, 587-606.

35. Lee, C.L.; Chen, Y.T.; Chung, L.L.; Wang, Y.P. Optimal design theories and applications of tuned mass dampers. Eng. Struct. 2006, 28, 43-53. [CrossRef]

36. Marano, G.C.; Greco, R.; Trentadue, F.; Chiaia, B. Constrained reliability-based optimization of linear tuned mass dampers for seismic control. Int. J. Solids Struct. 2007, 44, 7370-7388. [CrossRef]

37. Salvi, J.; Rizzi, E. Optimum tuning of Tuned Mass Dampers for frame structures under earthquake excitation. Struct. Control Health Monit. 2015, 22, 707-725. [CrossRef]

38. Tigli, O.F. Optimum vibration absorber (tuned mass damper) design for linear damped systems subjected to random loads. J. Sound Vib. 2012, 331, 3035-3049. [CrossRef]

39. Wong, K.K. Seismic energy dissipation of inelastic structures with tuned mass dampers. J. Eng. Mech. 2018, 134, 163-172. [CrossRef] 
40. Nigdeli, S.M.; Bekdaş, G.; Sayin, B. Optimum tuned mass damper design using harmony search with comparison of classical methods. AIP Conf. Proc. 2017, 1863, 540004.

41. Bertero, V.V. Strength and Deformation Capacities of Buildings under Extreme Environments; Prentice-Hall: Upper Saddle River, NJ, USA, 1980.

42. Vamvatsikos, D.; Cornell, C.A. Incremental dynamic analysis. Earthq. Eng. Struct. Dyn. 2002, 31, 491-514. [CrossRef]

43. Han, S.W.; Chopra, A.K. Approximate incremental dynamic analysis using the modal pushover analysis procedure. Earthq. Eng. Struct. Dyn. 2006, 35, 1853-1873. [CrossRef]

44. Sánchez-Olivares, G.; Tomás Espín, A. Design of planar semi-rigid steel frames using genetic algorithms and component method. J. Cons. Steel Res. 2013, 88, 267-278. [CrossRef]

45. Sánchez-Olivares, G.; Tomás Espín, A. Improvements in meta-heuristic algorithms for minimum cost design of reinforced concrete rectangular sections under compression and biaxial bending. Eng. Struc. 2017, 130, 162-179. [CrossRef]

46. Bilondi, M.R.S.; Yazdani, H.; Khatibinia, M. Seismic energy dissipation-based optimum design of tuned mass dampers. Struct. Multidiscip. Optim. 2018, 58, 2517-2531. [CrossRef]

47. Mazzoni, S.; McKenna, F.; Scott, M.H.; Fenves, G.L. The Open System for Earthquake Engineering Simulation (OpenSEES) User Command-Language Manual; Pennsylvania State University: University Park, PA, USA, 2006.

48. FEMA-356. Prestandard and Commentary for the Seismic Rehabilitation of Buildings; American Society of Civil Engineers: Reston, VA, USA, 2000.

49. Connor, J.J.; Laflamme, S. Applications of Active Control. In Structural Motion Engineering; Springer: New York, NY, USA, 2014; pp. 347-386.

50. Naderpour, H.; Naji, N.; Burkacki, D.; Jankowski, R. Seismic response of high-rise buildings equipped with base isolation and non-traditional tuned mass dampers. Appl. Sci. 2019, 9, 1201. [CrossRef]

51. Khatami, S.M.; Naderpour, H.; Razavi, S.M.N.; Barros, R.C.; Jakubczyk-Gałczyńska, A.; Jankowski, R. Study on methods to control interstory deflections. Geosciences 2020, 10, 75. [CrossRef]

52. Eskandar, H.; Sadollah, A.; Bahreininejad, A.; Hamdi, M. Water cycle algorithm-A novel metaheuristic optimization method for solving constrained engineering optimization problems. Comput. Struct. 2012, 110, 151-166. [CrossRef]

53. Siemaszko, A.; Jakubczyk-Gałczyńska, A.; Jankowski, R. The idea of using Bayesian networks in forecasting impact of traffic-induced vibrations transmitted through the ground on residential buildings. Geosciences 2019, 9, 339. [CrossRef]

54. Ibarra, L.F.; Krawinkler, H. Global Collapse of Frame Structures under Seismic Excitations; Pacific Earthquake Engineering Research Center: Berkeley, CA, USA, 2005; pp. 29-51.

55. Ibarra, L.F.; Medina, R.A.; Krawinkler, H. Hysteretic models that incorporate strength and stiffness deterioration. Earthq. Eng. Struct. Dyn. 2005, 34, 1489-1511. [CrossRef]

56. Lignos, D.G.; Krawinkler, H. Deterioration modeling of steel components in support of collapse prediction of steel moment frames under earthquake loading. J. Struct. Eng. 2011, 137, 1291-1302. [CrossRef]

57. Krawinkler, H.; Zareian, F.; Lignos, D.G.; Ibarra, L.F. Prediction of collapse of structures under earthquake excitations. In Proceedings of the 2nd International Conference on Computational Methods in Structural Dynamics and Earthquake Engineering COMPDYN 2009, Rhodes, Greece, 22-24 June 2009; paper no. CD449.

58. Kanai, K. An empirical formula for the spectrum of strong earthquake motions. Bull. Earthq. Res. Inst. 1961, 39, 85-95. (In Japanese)

59. Mohebbi, M.; Shakeri, K.; Ghanbarpour, Y.; Majzoub, H. Designing optimal multiple tuned mass dampers using genetic algorithms (GAs) for mitigating the seismic response of structures. J. Vib. Control 2013, 19, 605-625. [CrossRef]

60. Tajimi, H. A statistical method of determining the maximum response of a building structure during an earthquake. In Proceedings of the 2nd World Conference on Earthquake Engineering, Tokyo and Kyoto, Japan, 11-18 July 1960; pp. 781-797.

61. Wu, J.; Chen, G.; Lou, M. Seismic effectiveness of tuned mass dampers considering soil-structure interaction. Eart. Eng. Struc. Dyn. 1999, 28, 1219-1233. [CrossRef]

62. UBC-97, Uniform Building Code; International Conference of Building Officials: Whittier, CA, USA, 1997. 
63. Kamgar, R.; Rahgozar, R. Determination of critical excitation in seismic analysis of structures. Earth. Struc. 2015, 9, 875-891. [CrossRef]

64. Wong, K.K.; Johnson, J. Seismic energy dissipation of inelastic structures with multiple tuned mass dampers. J. Eng. Mech. 2009, 135, 265-275. [CrossRef]

(c) (2)

(C) 2020 by the authors. Licensee MDPI, Basel, Switzerland. This article is an open access article distributed under the terms and conditions of the Creative Commons Attribution (CC BY) license (http://creativecommons.org/licenses/by/4.0/). 